MATTHEW D. SHAPIRO

University of Michigan

\title{
Assessing the Federal Reserve's Measures of Capacity and Utilization
}

IN LATE 1988, capacity utilization in U.S. industry reached its highest level since early 1979. As measured by the Federal Reserve Board, capacity utilization in manufacturing industries was 84.6 percent in December 1988, a dramatic increase from the 70.3 percent trough of the 1982 recession. The 84.6 percent rate exceeds the postwar average by about a standard deviation, yet is still more than a standard deviation below the postwar maximum.

These relatively high and increasing rates of capacity utilization have, at least in some quarters, been taken as a signal that the long expansion that began in 1983 is drawing to its inevitable close. To some observers, moreover, higher utilization suggests a risk of accelerating inflation and the need for caution on the part of the Federal Reserve Board. ${ }^{1}$ Specifically, high measured capacity utilization is taken as a sign that the decomposition of nominal output growth into real growth and inflation has grown less favorable and that contractionary monetary policy is in order.

Capacity utilization is clearly one of the variables that the Federal Reserve's Open Market Committee (FOMC) considers, although there is some dispute about how it is to be interpreted. At a November 1, 1988,

I am grateful to Samuel Kortum for discussion and research assistance, to participants in seminars at the University of Rochester, the University of South Carolina, and Yale University for their comments, and to Richard D. Raddock and Charles Gilbert of the Industrial Output Section of the Board of Governors of the Federal Reserve System for suggestions and criticism.

1. See, for example, "The Outlook," Wall Street Journal, March 6, 1989, p. 1. 
meeting, one member of the FOMC "observed that the uncertainties in the outlook for inflation were compounded by the prospect that, with production resources at or close to full capacity, even small differences in demand pressures could have a disproportionate effect on the actual rate of inflation next year." ${ }^{2}$ The fear, clearly, is that increases in demand will lead to price rather than quantity response at high levels of measured utilization. Yet at what particular level the danger begins is open to debate. At the same November 1 meeting another member noted that "on the whole, price and wage developments were more favorable than might have been anticipated at current rates of capacity utilization." 3

Recent testimony before Congress by Alan Greenspan, Chairman of the Board of Governors, confirms that capacity utilization is one of the data he uses in judging the degree of tightness in the economy. But he goes on to say that "capacity is a somewhat elusive concept" and that the current levels of utilization might "well overstate the degree of price pressure." As reasons for discounting the current high rates of utilization, he mentions availability of goods from abroad and continuing undiminished vendor performance. ${ }^{4}$

My purpose in this paper is to assess whether the attention paid to measures of capacity utilization is warranted. As I will show, the withinyear variation in measured capacity utilization is almost entirely dominated by the within-year change in production. Therefore, period-byperiod changes in capacity utilization contain essentially no information beyond that contained in the change in production. Nevertheless there may be information in the level of utilization. If a high level indicates that the economy is approaching genuine capacity constraints, it should lower expected output growth; real output growth should be bounded by capacity constraints. Similarly, if low utilization indicates genuine excess capacity, it should increase expected output growth. This mean reversion could arise either through endogenous market mechanisms or the response of economic policy. A primary purpose of this paper is to look for evidence that output growth is constrained at high levels of measured capacity utilization.

Claims about the importance of capacity utilization are typically

2. Board of Governors of the Federal Reserve System (1989, p. 68).

3. Ibid.

4. Greenspan (1989). 
couched in terms of its importance for price change. Indeed, the view that high capacity utilization curtails growth and the view that it feeds inflation are closely related. For a given rate of growth in nominal demand, if capacity constrains real output growth, inflation must increase. A second aim of this paper is to evaluate the theory and evidence on the link between capacity utilization and price change. Rather than emphasize the well-known empirical link between high output and the absolute price level, I will examine the implications of high capacity utilization for relative prices-specifically, whether price-wage margins expand when capacity utilization is high.

Understanding the role of measured capacity in economic fluctuations can also help shed light on theories of the business cycle. Competing theories of business cycle fluctuations can be very roughly dichotomized: one paradigm accounts for movements in output as movements in the quantity produced relative to the amount that could be produced were the economy in long-run equilibrium; the competing paradigm accounts for movements in output as movements of the ability to produce in equilibrium. The former set of theories, which includes standard neoKeynesian theories, predicts that both capital and labor will be underused in cyclical downturns. If low measured capacity utilization indeed corresponds to Keynesian underuse of these factors, there should be more room for the economy to expand when capacity is high relative to output than when output approaches capacity. The latter set of theories predicts that output will be high when it is relatively cheap to produce. Changes in the cost of production can be either exogenous, as in real business cycle theories, or endogenous, as in theories of agglomeration and coordination economies. ${ }^{5}$ Whether the change in the cost of production, and therefore in the ability to produce, is exogenous or endogenous, these theories attribute changes in output to changes in the capacity of the economy to produce, given a physical quantity of inputs. Insofar as measured capacity does not respond to these innovations in the ability to produce, these theories suggest that an increase in measured capacity utilization signals an increase in the true capacity of the economy, not of output relative to capacity.

5. For real business cycle theories, see Prescott (1986). For a discussion of models of agglomeration, coordination, and economies of scale, see Hall (1988); Cooper and John (1988); Murphy, Shliefer, and Vishny (1989). 


\section{What Is Capacity Utilization?}

The Federal Reserve defines capacity utilization as the ratio of actual production to capacity, but leaves open the definition of capacity. ${ }^{6}$ Before discussing the Federal Reserve's data construction procedure, I will consider briefly what capacity means in theory. ${ }^{7}$ There are two possible definitions, the simplest of which is an engineering concept. It is defined by assuming: that some factors of production are fixed in the short run; that the elasticity of substitution between variable and fixed factors of production is very low; and that movements in production arise from shifts in demand rather than shifts in production possibilities. Capacity is then the greatest output that can be produced with these fixed factors. Under these assumptions, short-run changes in output equal short-run changes in utilization of fixed factors.

The notion of capacity that is appropriate for the firm's decisionmaking also reflects the firm's cost-minimization problem. For example, as output approaches the maximum engineering level, the firm may face high marginal costs other than costs due to the scarcity of fixed factors. Variable costs such as added wear and tear on capital equipment, overtime and shift wage premiums, and limits on the ability of a fixed labor force to work extraordinary hours for a sustained period probably make it optimal for production to remain below maximum engineering capacity. The cost-minimizing definition of capacity is the level of output high enough that fixed factors are not idle, but not so high that variable factors are making the marginal cost curve very steep. ${ }^{8}$

Finally, in practice, the definition of capacity depends on market conditions. Indeed, whether a plant will operate at all depends on the real wage and the real cost of other factors. For example, a fuel-hungry

6. With most economic data, the definition of the data is logically prior to the data collection. Physical output, revenue, wage rates, transactions prices, and so on are concepts that have meaning to economic decisionmakers and economists apart from any data collection activities of the government. Data collection by the government does not, of course, exactly correspond to the concepts that are meaningful to economists and economic agents.

7. See Klein and Long (1973) for a thorough discussion of conceptual issues in measuring capacity and utilization.

8. In the ex ante cost-minimization problem, the firms should weigh the cost of extra fixed factors against high variable costs in the event that the fixed factors are scarce. 
fertilizer plant might sharply limit or entirely curtail operations after a big increase in energy prices. ${ }^{9}$ Likewise, whether a plant can be operated profitably also depends on the demand side. A plant may be made obsolete economically by a shift in tastes away from the good that it produces. ${ }^{10}$ These changes in capacity arise in the absence of changes in the physical ability to transform inputs into output.

Observed capacity and utilization are based on the interaction of engineering and economic considerations within the firm and in the market. These interactions should be kept in mind in interpreting these data.

\section{The Federal Reserve's Measures of Capacity and Utilization}

The Federal Reserve publishes an index of capacity utilization for manufacturing as a whole with data available since 1948 and for industries at the two-digit standard industrial classification (SIC) level with data since 1967. ${ }^{11}$ The capacity indexes are matched to selected components of the Federal Reserve's industrial production series, although the Federal Reserve does not itself collect data relating to the capacity or utilization of industries in that series. Its preliminary estimate of capacity is generated by dividing the industrial production index by one of two independent survey estimates of capacity utilization, one by McGrawHill and the other by the Bureau of the Census. ${ }^{12}$

9. The situation becomes much more complicated if there is a third factor of production, say labor, that is substitutable with the hydrocarbons. If labor could be used to economize on the now dearer hydrocarbons, then output might not fall as much, but labor input would rise.

10. Admission of the demand side into the definition of capacity opens the question of market structure. A plant may be closed permanently because of an increase in market power even if there is no change in demand or costs. Similarly, a monopolist might hold excess capacity to deter entry.

11. This discussion of the procedures for estimating capacity utilization is closely based on Raddock (1985) and Board of Governors of the Federal Reserve System (1978).

12. The Bureau of Economic Analysis carried out a survey of utilization that was discontinued in 1983 over the Federal Reserve's objections. The Federal Reserve studied those data but used them only cautiously when they were available. Wharton Economic Forecasting Associates (WEFA) also publishes an index based on interpolating between peaks in output. See Klein and Long (1973). The Federal Reserve does not use this index, but uses the same methodology when no other data are available; see Raddock (1985, fn. 4). De Long and Summers (1988, pp. 454-57) propose a similar procedure for analyzing business cycle fluctuations. 
The McGraw-Hill survey, taken each December since 1955, provides the longest time series on capacity utilization. Based on a survey of a small sample of large manufacturing firms, it remains a major source of data for the aggregate manufacturing sector, although the Federal Reserve tries to use the best available data for individual industries.

Since 1974, the Bureau of the Census has conducted a large survey of manufacturing establishments-a survey for which the Federal Reserve financed the pilot study. ${ }^{13}$ Based on responses to the survey, the Census Bureau publishes utilization rates for the fourth quarter of the year for two-digit manufacturing industries and for selected three- and four-digit industries.

In certain industries, such as iron and steel, aluminum, auto assemblies, cotton spinning, paper and pulp, and electricity generation, more precise data are available on rated physical capacity of existing plants and are used by the Federal Reserve whenever they are available.

The data from the two surveys and the rated physical capacity are combined to yield the preliminary estimate of capacity. The Federal Reserve does not describe how it combines the three sources when more than one is available. It appears to proceed on a case-by-case basis to create a preliminary estimate that lies both between those implied by the competing data and above actual output as given by the respective industrial production series.

This preliminary capacity estimate does not immediately underlie any published statistic, but rather is an intermediate product in the Federal Reserve's data construction. It is subject to validation by comparison with capital stock data and to statistical adjustment and interpolation. The utilization rates from the surveys are less cyclical than production, so the "implied [capacity] indexes tend to rise sharply in an expansion after having dropped in a recession." 14 The Federal Reserve finds that these fluctuations are inconsistent with other data on capital stock and capacity in physical units and with direct reports of capacity expansion. To smooth the capacity figures implied by the utilization surveys $\left(I C_{t}\right)$, the Federal Reserve runs, for a particular industrial sector, the regression

$$
\log I C_{t}=\log K_{t}+\alpha+\sum \beta_{i} f_{i}(t)+\epsilon_{t},
$$

13. See Bureau of the Census (1987).

14. Raddock (1985, p. 762). 
where $K_{t}$ is one of the indicators of capacity (capital stock or physical capacity) and the $f_{i}(t)$ are functions of time (both time trends and constant shifts). ${ }^{15}$ The exponentiated fitted value from equation 1 is the "refined" estimate of capacity. If several indicators, $K_{t}$, of capacity are available, then several regressions are run and the fitted values are averaged. Because the refined capacity figures are based on fitted values, they reflect none of the year-to-year variation in the surveys of utilization. ${ }^{16}$ They do follow the smoothed pattern of the capacity implied by the utilization surveys insofar as the Federal Reserve adjusts the functions $f_{i}(t)$.

The McGraw-Hill and Census Bureau surveys refer only to the last month or last quarter of the year. The monthly capacity figures are interpolated with constant growth from end-of-year to end-of-year. The current year figures are extrapolated, taking account of expected capital investment reports of capacity expansion or related information when available. ${ }^{17}$

To take into account the large, predictable seasonal fluctuations in output of many industries, the Federal Reserve's capacity utilization figures are seasonally adjusted; implicitly, capacity and production are assumed to have the same seasonal pattern. Moreover, the Federal Reserve assumes that the seasonal peak in output is not sustainable throughout the year. The Federal Reserve describes these adjustments as "mov[ing] the capacity estimate from a peak engineering concept toward an economic concept." 18 The Federal Reserve presumes that capacity to meet seasonal peaks could not be used economically if

15. Ibid. Implied capacity $(I C)$ is industrial production divided by the survey utilization rate.

16. Year-to-year changes in the survey utilization rates can get back into the refined capacity estimates if the $f_{i}(t)$ function is not parameterized parsimoniously.

17. The current year's figures might be adjusted "on the basis of new information," according to Raddock (1985, p. 762). I assume this information refers to explicit information about capacity expansion or contraction, not news about actual production.

18. Raddock (1985, p. 764). The definition of economic concept appears to be circular. "Establishments clearly are able to produce at the peak levels of output that occur at times of seasonal highs. The lower levels of output encountered during other periods of the year, however, leave considerable slack physical capacity. In an economic sense, some of this margin of capacity is not redundant; it gives the establishment the needed flexibility to operate in times of seasonal stress. The Federal Reserve aims to treat this cushion of flexibility as serving an economic function." Ibid. 
demand happened to be unusually high during a season that is usually one of low demand.

The Federal Reserve also makes adjustments to the estimated capacities to correct for the different levels of utilization implied by the various data sources. They estimate capacity so that production does not exceed capacity (except in rare instances) and so that production is not chronically below "normal" capacity utilization. The consequence of these adjustments is, as the Federal Reserve's documentation makes clear, that the published utilization figures should be given no cardinal interpretation.

\section{Evaluation of the Federal Reserve's Measures of Capacity Utilization}

The Federal Reserve's capacity utilization rate should be viewed with the caution that economists customarily reserve for data based on subjective survey questions. ${ }^{19}$ In this case the subjectivity arises because managers are asked to rate their existing production relative to an only loosely specified norm. Although managers clearly should know their current output, "normal" or "ideal" output may not be a measure they need to know to do their jobs. Moreover, managers' views of "normal" might vary across time and across firms and in general need have little to do with what might be appropriate for an aggregate measure of utilization.

In a number of industries, high quality data on physical capacity are available from commercial or industrial sources. Utilization data for these industries should be viewed with less skepticism than that for industries-including the aggregates-where the estimates are based on a survey. As discussed earlier, however, even an engineering concept is difficult to interpret.

\section{Vagueness of Definition}

Although the McGraw-Hill survey questions about capacity are undefined and open-ended, the Census Bureau survey is much more

19. The building blocks of much economic data are based on surveys or censuses that require individuals or firms to fill in a form expressly for the purpose of providing the government with data. But many of these forms request data that firms already have available (production, sales, wage data). 
explicit. ${ }^{20}$ The firms are asked to report the value of production for actual operations, preferred operations, and practical capability. These concepts are explicitly defined. Preferred operations are "a level of operations that you would prefer not to exceed because of costs or other consideration. Implicit in the idea of a preferred level of operations is that there is a level of operations at which profits are maximized. This is a level where marginal revenue equals marginal costs." ${ }_{21}$ In defining preferred operations, the Census Bureau does not indicate why the profit-maximizing output would ever differ from the actual output. Presumably, adjustment costs give rise to dynamics in the profitmaximization problem. Although the definition is spelled out explicitly, it is unclear what economic concept it is capturing.

Although the Census Bureau does not make reference to such in defining it, practical capacity appears to refer to the engineering maximum of production. It is defined as follows: "The maximum level of production that this establishment could reasonably expect to attain using realistic employee work schedule and the machinery and equipment in place." ${ }^{22}$ Moreover, the respondents are explicitly instructed to ignore increasing marginal cost (from overtime premiums, for example) when calculating practical capacity.

The Census Bureau definitions highlight the difficulty of trying to rely upon either an economic or an engineering definition of capacity alone. The presumption that corner solutions are not important pervades neoclassical analysis. Specifically, as long as elasticities of substitution are not strictly zero, it is always possible to increase output even if some factors are fully employed. It might, however, be very costly to do so. For example, the Census Bureau states that "the number of shifts and hours of plant operation that can be reasonably attained by your plant in your community" is a constraint on preferred operation. But what seems reasonable to a community will depend on the wage paid. Likewise, engineering estimates of capacity must be taken as based on given prices and wages. ${ }^{23}$

The vagueness in the definition of capacity does not apply only to the

20. See Business Conditions Digest (1977).

21. See Bureau of the Census (1987, Appendix A, MQ-C1 Form and Instructions).

22. Ibid.

23. Engineering estimates of capacity are a function of prices, just as geological estimates of petroleum reserves are predicated on what is economical to extract and tend to increase with the price of oil. 
use of the surveys. The Federal Reserve brings many sources of data, as well as human judgment, to bear on capacity, but it is never explicit about either what is being measured or the purposes of those measurements.

\section{Seasonality}

Recent research has highlighted the importance of seasonal fluctuations in economic activity. The seasonal movements in output are as large as those over a typical business cycle; the joint movements of output and input look similar at seasonal and business cycle frequencies. ${ }^{24}$ More to the point, production and sales move closely together, so inventories do not appear to smooth production over the seasonal changes in demand, at least at the two-digit level..$^{25}$

By assuming that the seasonal peaks in output cannot be sustained on a year-round basis, the Federal Reserve avoids reporting seasonal excess capacity. Given that the Federal Reserve has no information on the seasonality of capacity, its decision does not seriously compromise the utilization figures. Seasonal utilization can be calculated from the seasonally unadjusted industrial production data under the assumption that capacity is not seasonal. Nonetheless, industries that have highly seasonal production will in fact have substantial scope for expanding output in months where output is seasonally low even if reported utilization rates are high.

The seasonality of production is also an issue in the data collection. The McGraw-Hill data are from December of each year; the Census data, from the fourth quarter, a seasonal peak in production for manufacturing industries. ${ }^{26}$ If the aim of the surveys is to measure the outer envelope of productive capabilities, then the dating of the surveys is a happy coincidence.

\section{The Numerator of Capacity Utilization}

The Federal Reserve defines capacity utilization relative to its indexes of industrial production; its published capacity utilization figures equal

24. See Barsky and Miron (1989).

25. See Miron and Zeldes (1988).

26. See Barsky and Miron (1989). 
industrial production divided by its estimate of capacity. How certain components of industrial production are estimated determines their suitability as the numerator in capacity utilization. There are three sources of data for industrial production: actual production, kilowatt hours of electricity consumed by industry, and production worker hours in industry. In the total industrial production index, 42.9 percent of the data are actual production, 30.0 percent are kilowatt hours, 25.2 percent are production worker hours, and 1.9 percent are kilowatt and production worker hours combined. ${ }^{27}$ For industrial components in which accurate and timely monthly data on physical units of production are not available, the Federal Reserve infers physical production from the input data.

To infer production from input, the Federal Reserve multiplies the input series by a time-varying coefficient called the production factor coefficient (PFC): "The PFCs are estimates from historical data, and they reflect the past trend and cyclical relationships between production and its input factors." 28 The Federal Reserve does recognize the phenomenon of short-run increasing returns and consequently makes a cyclical adjustment in the relation between input and output. Some such adjustment is clearly appropriate if the objective is an optimal estimate of production. Yet the appropriateness of a particular adjustment will depend on both the form of the production function and the source of the input fluctuations. Note, however, that the model underlying the PFCs embodies a theory of, among other things, capacity utilization. Consequently, inferences about utilization drawn from the series in which production is imputed are affected by the Federal Reserve's implicit model of capacity utilization. This problem compromises the meaning of the utilization series in which the numerator is based on input data. For this reason, the analysis of this paper is based mainly on industries in which industrial production is constructed primarily from data on output.

The problem of inferring production from input series is largely an issue for the within-year variation of the production series. On an annual

27. See Board of Governors of the Federal Reserve System (1986, p. 34). Figures are the 1977 proportions in value added; they do not add to 100.0 because of rounding. See also Miron and Zeldes (1989) for a further discussion of this and other important issues in measuring production.

28. Board of Governors of the Federal Reserve System (1986, p. 44). 
basis, data from various censuses provide actual production data for most industries.

\section{Incremental Information in Short-Term Changes in Utilization}

Except for extraordinary adjustments based on miscellaneous information, the capacity figures for the ongoing year are linearly extrapolated at the growth rate of capacity from the previous year. All the withinyear variation in capacity utilization thus arises from variation in industrial production. ${ }^{29}$ Surprises in capacity utilization carry no information not already embodied in the production figures.

Although this claim is clearly established based on the reading of the Federal Reserve's documentation, it can also be verified by direct examination of the data. Table 1 presents ordinary least squares regressions of the growth rate in capacity utilization on a constant and the growth rate in industrial production for various industries. The slope coefficients are very precisely estimated to be unity, and the growth rate in production explains virtually all of the month-to-month changes in utilization. The third and fourth columns in table 1 report the same regression with dummies for calendar years included and with the January growth rate excluded. In these regressions that account for annual shifts in capacity growth rates, the fit is even higher.

The Federal Reserve's professional staff is clearly aware of this issue: “The Federal Reserve's capacity estimates reflect long-term production trends, businessmen's judgment concerning the degree of utilization of their facilities, and the pattern of real investment over the course of the business cycle. These estimated capacity indexes appear to be reasonably good measures of production capabilities over time, but they should not be considered to be accurate indicators of short-term changes. . . ." ${ }^{30}$ Notwithstanding this careful disclaimer, capacity utilization does appear to be discussed as if it were a business cycle indicator independent of production. The results of table 1 and the statement of purpose quoted above suggest that it is necessary to look beyond the high-frequency movements in utilization. Later I investigate whether

29. When the historical data are revised, the capacity figures are adjusted in light of new information (including production).

30. Board of Governors of the Federal Reserve System (1978, p. 3). 
Table 1. Regressions of Monthly Growth in Capacity Utilization on Growth in Industrial Production, Various Industries ${ }^{a}$

\begin{tabular}{|c|c|c|c|c|}
\hline \multirow[b]{2}{*}{ Industry } & \multicolumn{2}{|c|}{ No dummies } & \multicolumn{2}{|c|}{ Year dummies ${ }^{\mathrm{b}}$} \\
\hline & IP & $R^{2}$ & $I P$ & $R^{2}$ \\
\hline Manufacturing & 1.001 & 0.991 & 0.989 & 0.995 \\
\hline Mining & 0.996 & 0.990 & 0.998 & 0.997 \\
\hline Primary metals & 1.003 & 0.998 & 1.001 & 1.000 \\
\hline Paper & 0.994 & 0.997 & 0.994 & 0.999 \\
\hline Motor vehicles & 0.999 & 0.998 & 0.999 & 1.000 \\
\hline Petroleum & 0.989 & 0.984 & 0.999 & 0.999 \\
\hline Chemicals & 0.993 & 0.981 & 0.995 & 0.996 \\
\hline Electric utilities & 0.992 & 0.984 & 1.001 & 0.999 \\
\hline Manufacturing (extended period) & 0.992 & 0.989 & 0.987 & 0.994 \\
\hline
\end{tabular}

a. Data are monthly from February of 1967 through December of 1988 and are seasonally adjusted. Table reports the estimated coefficient of the growth rate in industrial production $(I P)$ in a regression with the growth rate in capacity utilization $(C U)$ as a dependent variable.

b. Regressions include dummy variables for all but one calendar year.

c. Sample runs from February of 1948 through December of 1988.

low-frequency movements in utilization are useful business cycle indicators.

\section{Survey versus Capital Stock Data in Measured Capacity}

While the Federal Reserve makes clear the range of data it uses in determining its estimate of capacity, its published description of its procedures does not reveal the weight it puts on the various series. These weights can, however, be approximated by comparing the Federal Reserve's capacity estimate to the raw data. Table 2 presents regressions of the log level of the Federal Reserve's estimate of capacity on a constant, the log of the Bureau of Economic Analysis's estimate of the capital stock, and the log of the level of capacity implied by the McGrawHill utilization survey. The McGraw-Hill capacity figure is inferred by dividing its capacity utilization data into the Federal Reserve's industrial production index.

For aggregate manufacturing, the Federal Reserve gives the BEA estimate of the capital stock a weight of about 60 percent and the McGraw-Hill survey a weight of about 40 percent in constructing its capacity estimate since 1967 . In the years before 1967, the McGraw-Hill survey has a much greater weight. 
Table 2. Regressions Explaining Federal Reserve Capacity Measures Using BEA Capital Stock and McGraw-Hill Capacity ${ }^{\mathrm{a}}$

\begin{tabular}{|c|c|c|c|c|}
\hline \multirow[b]{2}{*}{ Industry } & \multirow[b]{2}{*}{$\begin{array}{l}\text { BEA } \\
\text { capital } \\
\text { stock }\end{array}$} & \multirow[b]{2}{*}{$\begin{array}{c}\text { McGraw-Hill } \\
\text { capacity } \\
\text { level }^{\mathrm{b}}\end{array}$} & \multicolumn{2}{|c|}{ Summary statistic } \\
\hline & & & $\begin{array}{c}\text { Standard } \\
\text { error of } \\
\text { estimate }\end{array}$ & $\begin{array}{l}\text { Durbin- } \\
\text { Watson }\end{array}$ \\
\hline Manufacturing ${ }^{\mathrm{c}}$ & $\begin{array}{c}0.64 \\
(0.09)\end{array}$ & $\begin{array}{c}0.43 \\
(0.08)\end{array}$ & 0.014 & 1.3 \\
\hline Mining $^{d}$ & $\begin{array}{c}0.40 \\
(0.06)\end{array}$ & $\begin{array}{c}-0.03 \\
(0.06)\end{array}$ & 0.018 & 0.3 \\
\hline Primary metals ${ }^{\mathrm{e}}$ & $\begin{array}{c}0.48 \\
(0.11)\end{array}$ & $\begin{array}{c}0.32 \\
(0.04)\end{array}$ & 0.018 & 1.7 \\
\hline Paper & $\begin{array}{c}0.40 \\
(0.08)\end{array}$ & $\begin{array}{c}0.60 \\
(0.08)\end{array}$ & 0.022 & 1.4 \\
\hline Motor vehicles ${ }^{c}$ & $\begin{array}{c}0.97 \\
(0.16)\end{array}$ & $\begin{array}{c}0.35 \\
(0.11)\end{array}$ & 0.061 & 1.0 \\
\hline Petroleum ${ }^{c}$ & $\begin{array}{c}0.05 \\
(0.06)\end{array}$ & $\begin{array}{c}1.04 \\
(0.09)\end{array}$ & 0.027 & 1.4 \\
\hline Chemicals $^{c}$ & $\begin{array}{c}0.48 \\
(0.14)\end{array}$ & $\begin{array}{c}0.66 \\
(0.09)\end{array}$ & 0.028 & 1.5 \\
\hline Manufacturing (extended period) ${ }^{\mathrm{f}}$ & $\begin{array}{c}0.43 \\
(0.09)\end{array}$ & $\begin{array}{c}0.60 \\
(0.08)\end{array}$ & 0.017 & 1.2 \\
\hline
\end{tabular}

a. Dependent variable is Federal Reserve capacity $(I P / C U)$. Table reports estimated regression coefficients of the BEA capital stock and the McGraw-Hill capacity level. Numbers in parentheses are standard errors. Data are annual, end-of-year values. All variables enter as natural logs.

b. Capacity level implied by the McGraw-Hill survey (FRB IP divided by the McGraw-Hill utilization rate).

c. Sample 1967-86.

d. Sample 1967-82.

e. Sample 1973-86.

f. Sample 1954-86.

The Federal Reserve uses the information differently in different industries. For motor vehicles, it gives little weight to the survey, but in petroleum refining it gives all the weight to the survey. In the other manufacturing industries, the Federal Reserve uses a mixture of the data. In mining, the Federal Reserve does not appear to use the McGrawHill survey, but appears to be relying on information in addition to the capital stock.

\section{The Federal Reserve Data}

Before proceeding to further analysis, a quick look at trends in production and capacity, and, implicitly, capacity utilization, is in order. Here I illustrate graphically Federal Reserve data for aggregate manu- 
facturing and for selected manufacturing and nonmanufacturing industries.

Although all the difficulties in measuring utilization discussed in detail in the previous section arise in the aggregate manufacturing index, I include data for aggregate manufacturing because they are central to most discussions of utilization.

Capacity utilization measures are most likely to be meaningful for industries for which physical data on production and capacity are available and used by the Federal Reserve in both the industrial production indexes and in the capacity estimates. Here and subsequently I focus on mining (standard industrial classification 10-14), primary metals (SIC 33), paper (SIC 26), motor vehicles (SIC 371), petroleum (SIC 29), chemicals (SIC 28), and electric utilities (SIC 491, part of 493). ${ }^{31}$ These industries also provide a mix of process and batch production and of durables and nondurables.

In addition, I show data for iron and steel (SIC 331 and 332), aluminum (SIC 3334), and aerospace and miscellaneous transportation (SIC 37276 and 379), which are included in the later analysis of the output surprises. The iron and steel and aluminum industries have products that are narrowly defined and are well measured. Additionally, they are industries in which measured utilization is often very high. Aerospace does not meet the criterion of having well-measured production, but it may be of special interest because its order backlogs are especially large and variable. ${ }^{32}$

The data analyzed in this section are quarterly, with quarterly figures taken to be the last month in the quarter. The data, which begin for aggregate manufacturing in 1948 and for two-digit industries in 1967, are available through December 1988.

Figure 1 gives the level of the Federal Reserve's industrial production index and the level of capacity implied by dividing production by capacity

31. The fraction of actual product used to estimate industrial production in these industries is as follows: mining, 0.95 ; primary metals, 0.91 ; paper, 0.99 ; motor vehicles, 0.66; petroleum, 0.95; chemicals, 0.33; electric utilities, 1.0. See Board of Governors of the Federal Reserve System (1986, appendix table A.1). In motor vehicles, most of the production imputed from hours is in the production of original-equipment parts. This component is benchmarked annually to new car and truck production. In chemicals, there is physical production data on crude materials but not on processed ones (drugs, soap, cosmetics).

32. Measurement output of processes that take several periods to complete, such as building airplanes, is particularly problematic. 
Figure 1. Capacity and Production, Aggregate Manufacturing, 1948-88, and Selected Industries, 1967-88

Log scale

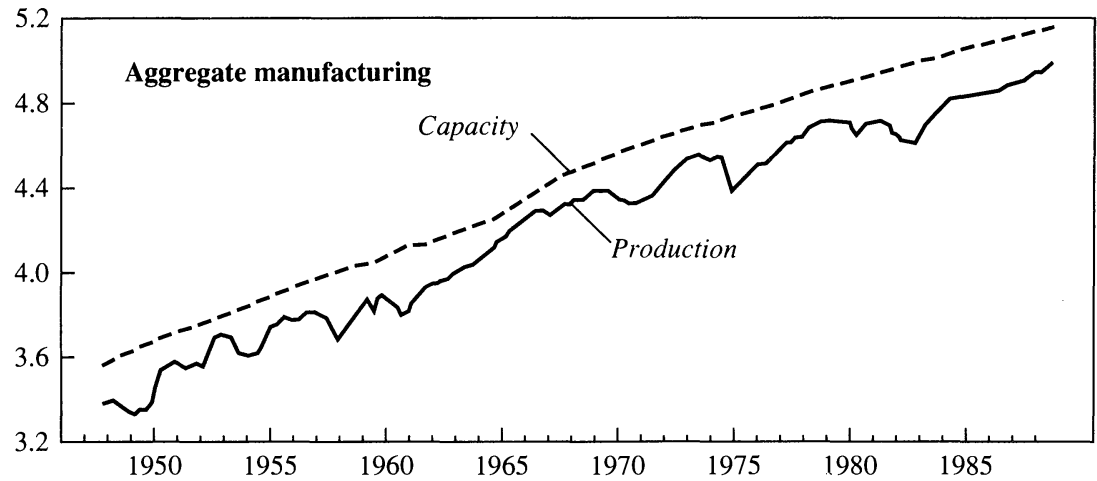

Log scale

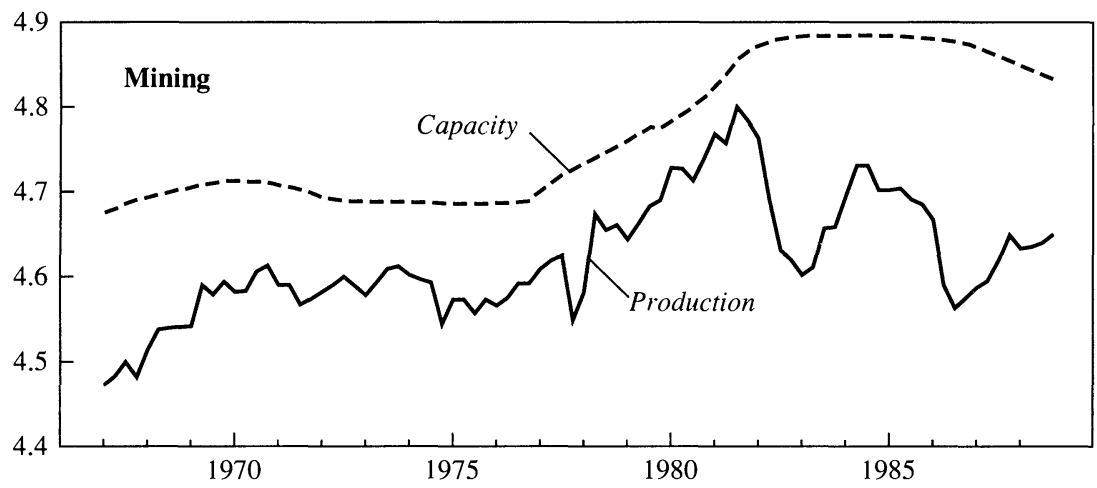

Log scale

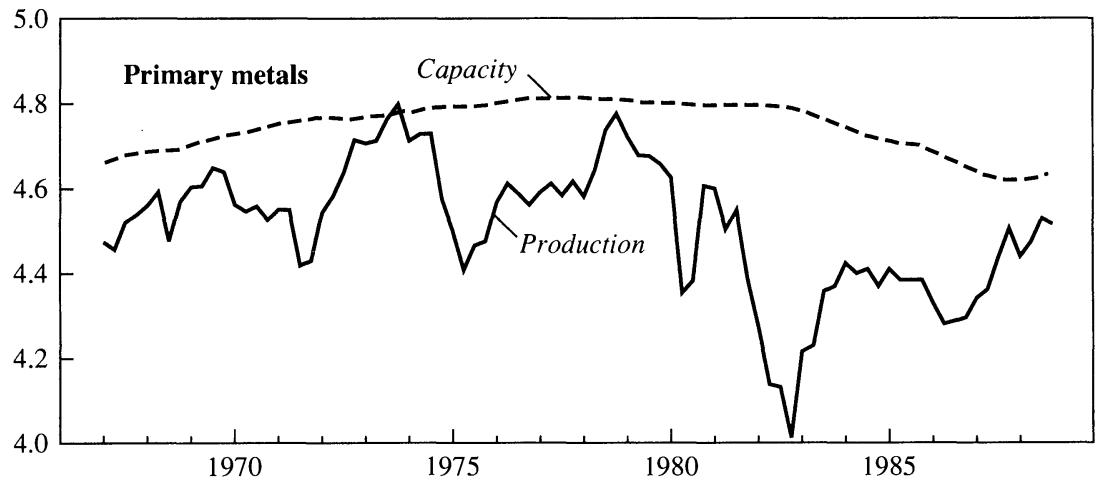


Matthew D. Shapiro

Figure 1. (continued)

Log scale

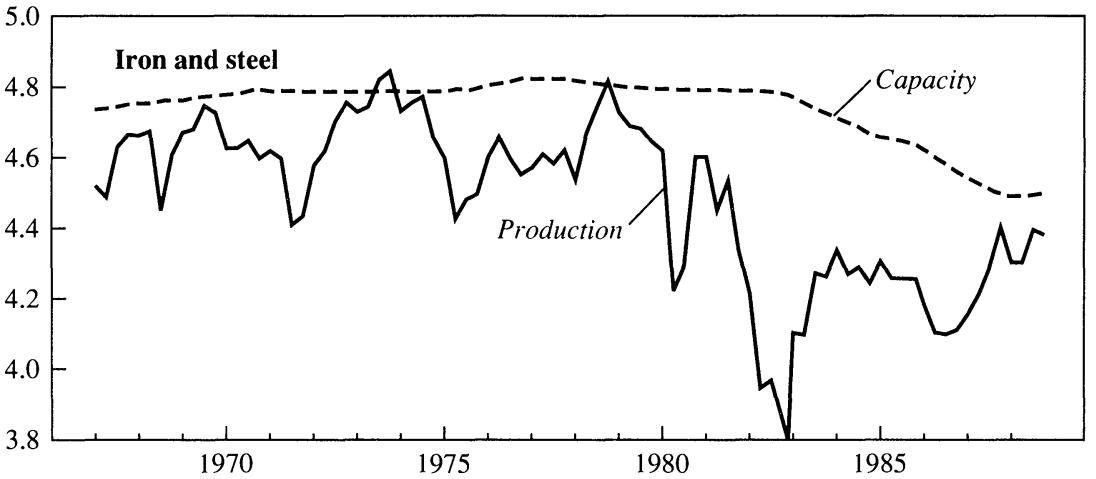

Log scale

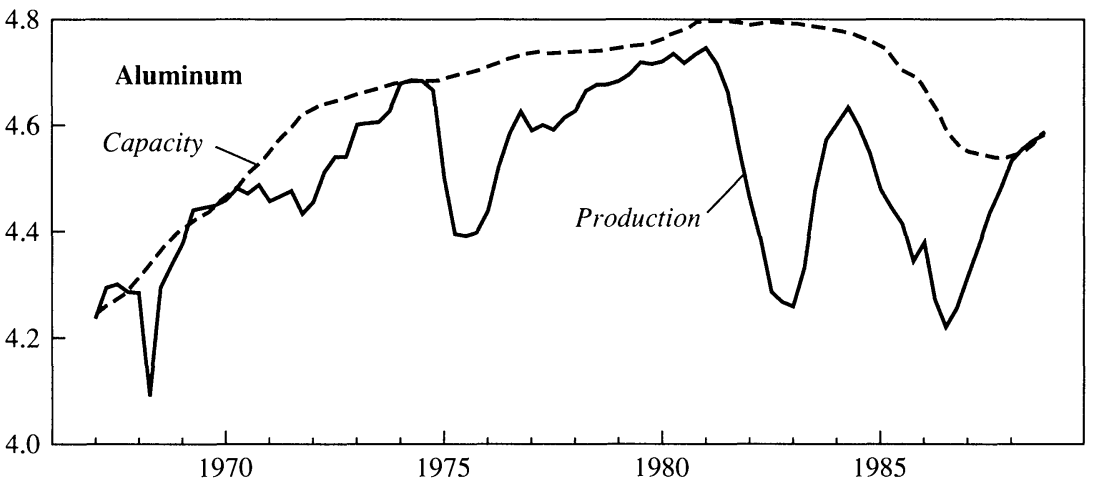

Log scale

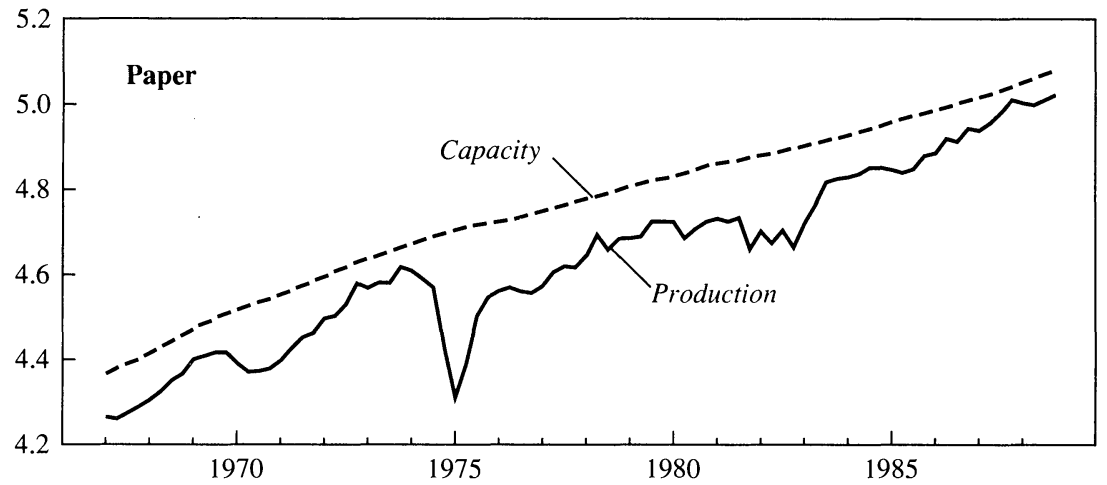


Figure 1. (continued)

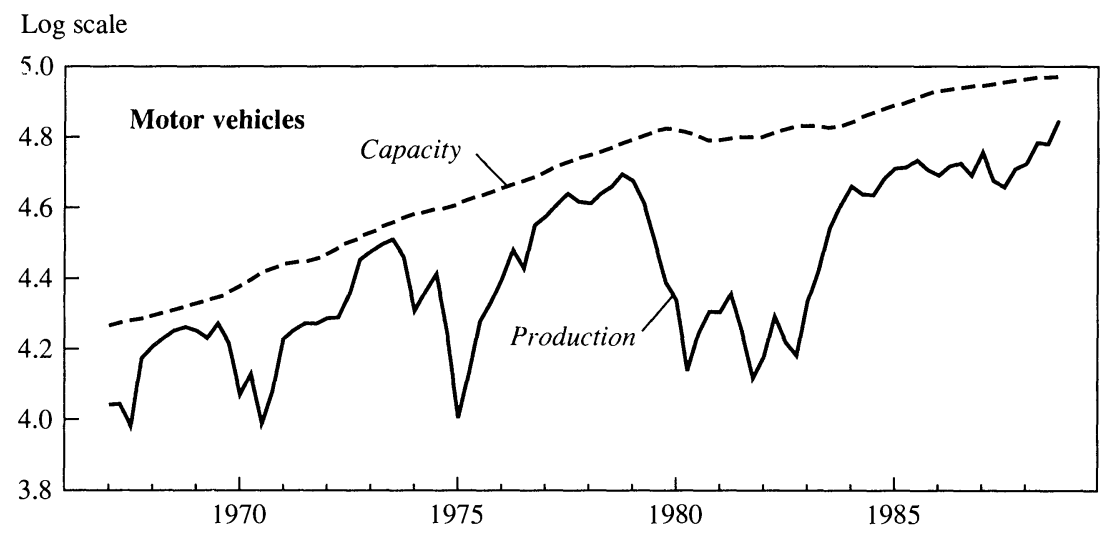

Log scale

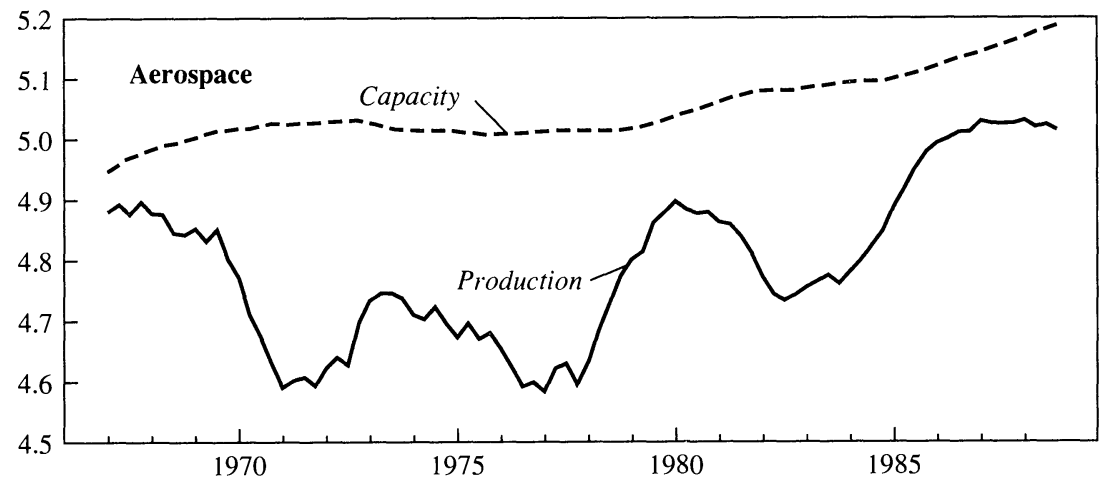

Log scale

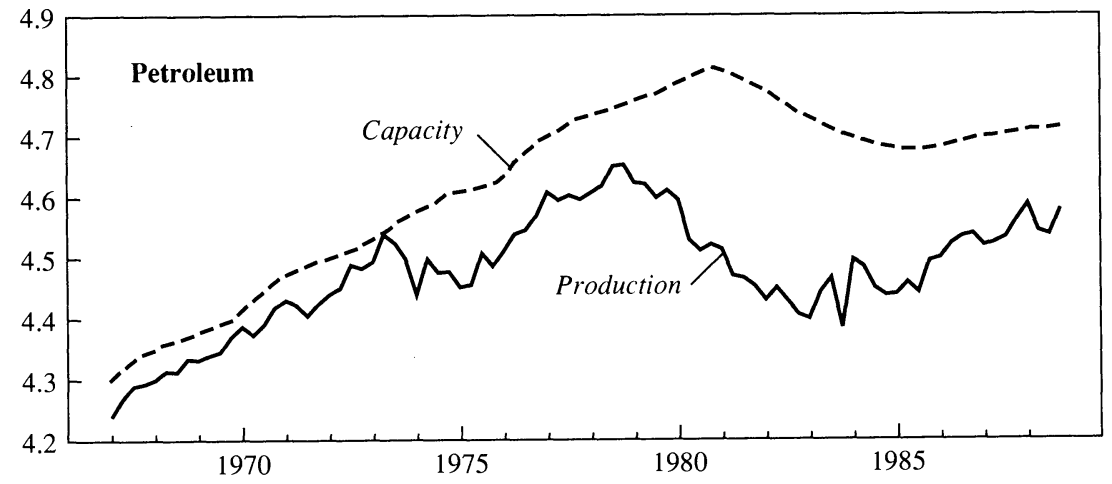


Figure 1. (continued)

Log scale

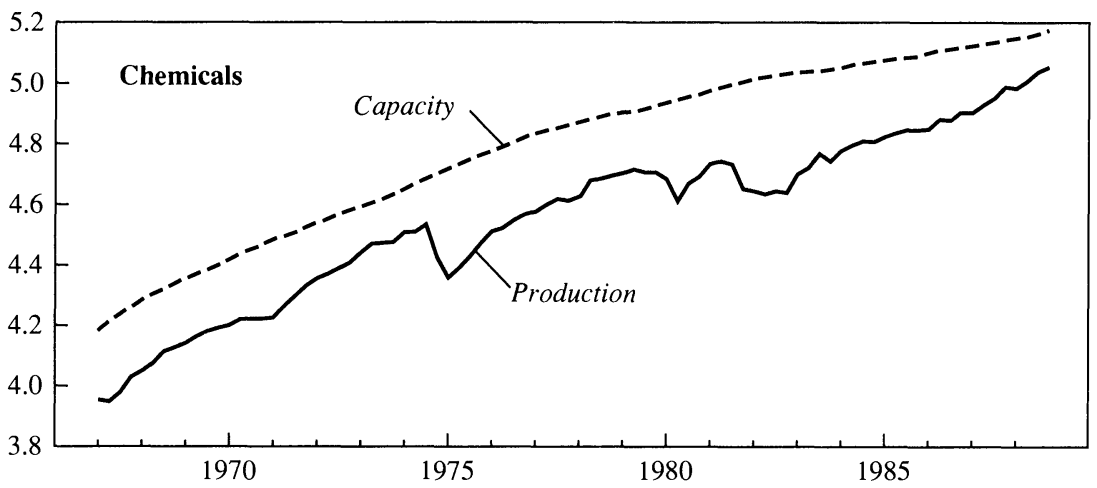

Log scale

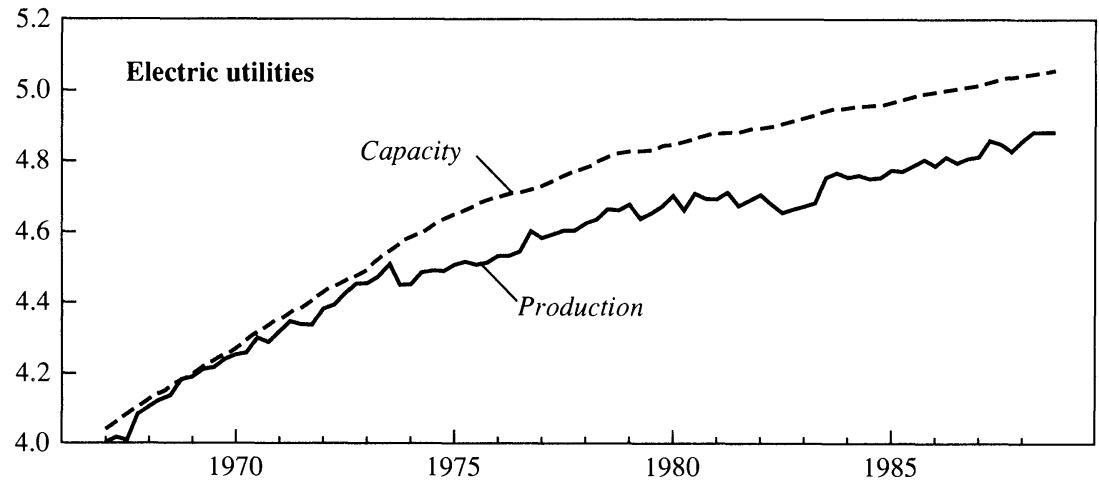

utilization. As the discussion of the data construction procedures suggests, capacity is much less variable than production. Yet there are interesting low-frequency movements in the capacity series. Given the data construction procedures, it is not surprising that aggregate manufacturing capacity is so smooth. It grows steadily until the mid-1960s, when it accelerates for several years. It then decelerates, returning to a steady, but slightly slower, growth rate in the 1970s and 1980s. The level of utilization is currently high relative to the past decade, but not to previous peaks.

Mining capacity has major low-frequency movements. In the late 1960s, capacity increases less slowly than production; it falls during 
most of the 1970s. It accelerates quickly after the second oil shock, only to flatten and fall after 1982. Movements in utilization in mining are dominated by the big decline of production in 1982 .

Primary metals output during the peak in 1973 actually surpasses capacity. Utilization falls dramatically during the 1982 recession with capacity following output down until 1988 when it begins to rise. Utilization is approaching the levels achieved in previous peaks. Both iron and steel and aluminum show a number of periods, including the recent one for aluminum, where production is at measured capacity.

Of the industries studied here, paper has the steadiest capacity growth. Except for a slight shift in the growth rate of capacity in the mid-1970s, all the variation in utilization arises from variation in production.

Motor vehicles capacity grows fairly smoothly until 1980, when it begins to grow haltingly. Like mining, primary metals, and petroleum, motor vehicles experiences a dramatic drop in production in the early 1980 s, but unlike these industries, its capacity does not fall dramatically.

Capacity in petroleum refining continues to grow at the pre-OPEC rate through the second oil shock despite the dramatic, persistent stepdown in measured utilization in 1974. Unlike that in the other industries, production falls steadily from the end of 1978 until the middle of the 1980s. Capacity continues to grow until 1981 and then falls rapidly until 1985, when it begins to rise, but more slowly than does production.

Chemicals have smooth capacity growth except for a pronounced slowdown in the rate of capacity accumulation in the second half of the sample. This slowdown is important for recent experience because it implies very high levels of utilization in 1988.

Electric utilities have capacity and production growth of about the same rate and therefore flat utilization except for a one-time downward shift in production relative to capacity in 1974 . Because the change in utilization in electric utilities is dominated by this non-business cycle movement, utilities are excluded from the remainder of the analysis.

All these industries are currently showing the highest capacity utilization seen during the 1980s. With the exception of aluminum and chemicals, however, measured levels of utilization are not extreme relative to the entire sample period. Capacity looks tight at the end of the 1980 s relative to the early part of the decade only because there was so much slack after the 1982 downturn. The tightness of measured capacity utilization at the end of the 1980s arises because of the 
combination of strong growth in production and slow or even negative growth in capacity in many industries.

The Federal Reserve's data construction procedure assures that capacity utilization does not permanently drift either too high or too low. Given the sustained low levels of production in the early 1980s, the Federal Reserve's procedures might have pulled down their estimates of capacity. For industries where it has specific measures of capacityincluding primary metals and petroleum refining—reductions in capacity are based on explicit information about permanent plant closings.

\section{Does the Level of Utilization Affect the Forecast of Production?}

Although short-term changes in measured utilization seem to have no information beyond that contained in changes in production, the level of capacity utilization could affect the future growth of output. An increment to production at high levels of utilization could carry very different information than an increment at low levels of utilization. This section, therefore, asks whether lags of the level of utilization help forecast production.

It should be noted that there is a theoretical ambiguity in the relationship between production and capacity, especially at the aggregate level. High capacity utilization might lower one's forecast of output if it indicates physical constraints on the amount that output can expand. On the other hand, it might also signal the need for higher capital accumulation, which in turn could increase the forecast of future output as production in capital-goods-producing industries expands. This direction of causation from utilization to output should not be important at the industry level insofar as industries do not produce their own capital goods. Disaggregation by industries alone will not, however, eliminate this direction of causality as long as aggregate and industrial movements in capacity are correlated. This issue is addressed more directly in a subsequent section that examines the relationship between capacity utilization and investment.

\section{Linear Forecasting Equations}

The simplest way to evaluate whether capacity or capacity utilization helps forecast production is to estimate a univariate forecasting equation 
for production and to test whether the capacity data have any incremental explanatory power. Admittedly, given how closely utilization and production move, it is unlikely that this approach will yield promising results. Yet, if enough lags are included, the simple linear regressions might capture the information in the low-frequency movements in capacity apparent in figure 1 .

Results of estimating forecasting equations for industrial production (denoted $I P$ ) are given in table 3 , which reports estimates of a logdifferenced specification. Each of the equations includes twelve lags of the dependent variable and of capacity utilization $(C U)$. The first column reports the adjusted coefficient of determination $\left(\bar{R}^{2}\right)$ for the fitted equation with the coefficients on the capacity measures set to zero. The last column reports the marginal significance level of the $F$-test of the null hypothesis that the coefficient of each lag of the capacity measures is zero.

Although the lagged dependent variables in the regressions could be picking up the mean reversion meant to be captured by capacity utilization, such is not the case. Except for aggregate manufacturing, the lagged dependent variables are insignificant and small. In manufacturing, the coefficients have a positive sum, implying that the level of production moves further away from its initial position after a shock rather than reverting to its prior mean. ${ }^{33}$

The regressions reported in table 3 show little explanatory power even for the lagged growth rates. Moreover, adding the utilization rate usually reduces the fit of the equation, and the added variables are never statistically significant. Forecasts of the growth rate could not be improved by taking into account variation in capacity utilization in this linear regression setting.

The tests presented in table 3 may lack power because of the long lags and colinearity of changes in production and utilization. More parsimonious estimates are presented in table 4 . The first row for each industry presents regressions of production growth on one lag of capacity utilization and four lags of the dependent variable. In these regressions, the lagged capacity utilization is significantly negative in aggregate manu-

33. This characterization of the process for manufacturing production is similar to Campbell and Mankiw's (1987) characterization of aggregate GNP. 
Table 3. Regressions Using Lagged Industrial Production and Capacity Utilization to Predict Industrial Production ${ }^{\text {a }}$

\begin{tabular}{lccc}
\hline & \multicolumn{2}{c}{$\bar{R}^{2}$} & \\
\cline { 2 - 3 } \multicolumn{1}{c}{ Industry } & $\begin{array}{c}\text { CU coefficient } \\
\text { constrained } \\
\text { to be zero }\end{array}$ & $\begin{array}{c}\text { CU coefficient } \\
\text { freely } \\
\text { estimated }\end{array}$ & $\begin{array}{c}\text { p-value for } \\
\text { CU coefficients } \\
\text { equal to zero }\end{array}$ \\
\hline Manufacturing & 0.184 & 0.161 & 0.59 \\
Mining & -0.006 & 0.038 & 0.28 \\
Primary metals & 0.015 & -0.032 & 0.68 \\
Paper & 0.081 & 0.060 & 0.57 \\
Motor vehicles & -0.032 & -0.063 & 0.60 \\
Petroleum & 0.086 & 0.050 & 0.65 \\
Chemicals & -0.011 & 0.062 & 0.20 \\
Manufacturing (extended period) & 0.193 & 0.187 & 0.54 \\
\hline
\end{tabular}

a. Sample period is quarterly, 1970:2-1988:4, where quarterly observations are taken to be the last monthly observation in the quarter. Results reported are from regressions, for each industry, of the change in natural $\log$ of $I P$ on a constant plus 12 lags of dependent variable plus 12 lags of $C U$.

b. Marginal significance level of the $F$-test of the null hypothesis that coefficient on each lag of the capacity measures is zero.

c. Sample period 1951:2-1988:4.

facturing and all the industries except petroleum. These findings do appear to suggest that growth is lower the higher is capacity utilization, that is, that there is mean reversion in production where the Federal Reserve's measure of capacity is the conditional mean.

The significance of capacity utilization in the growth rate regressions could arise because some stationary function of the level of output belongs in the equation rather than because capacity is the appropriate detrending variable. To check this possibility, the second row for each industry adds detrended log industrial production (variable Detrended) to the equations. The coefficient of detrended production is significantly negative, but the coefficient of utilization becomes insignificant and usually positive. These findings suggest that there is mean reversion in the process for output growth not reflected in the univariate autoregressive specification, but that the conditional mean is better measured by a simple, linear trend than by the Federal Reserve Board's measure of capacity. ${ }^{34}$

34. These results should, however, be interpreted with caution. Indiscriminant inclusion of trends in regressions can lead to spurious results. 
Table 4. Parsimonious Regressions Using Lagged Industrial Production and Capacity Utilization to Predict Industrial Production ${ }^{\mathrm{a}}$

\begin{tabular}{|c|c|c|c|c|c|c|c|}
\hline Industry & $\begin{array}{l}\Delta \log \\
I P_{(-1)}\end{array}$ & $\begin{array}{l}\Delta \log \\
I P_{(-2)}\end{array}$ & $\begin{array}{l}\Delta \log \\
I P_{(-3)}\end{array}$ & $\begin{array}{l}\Delta \log \\
I P_{(-4)}\end{array}$ & $C U_{(-1)}$ & Detrended $^{\mathrm{b}}$ & $\bar{R}^{2}$ \\
\hline \multirow[t]{2}{*}{ Manufacturing } & $\begin{array}{c}0.51 \\
(0.11)\end{array}$ & $\begin{array}{c}0.02 \\
(0.13)\end{array}$ & $\begin{array}{c}0.10 \\
(0.13)\end{array}$ & $\begin{array}{c}0.14 \\
(0.12)\end{array}$ & $\begin{array}{r}-0.22 \\
(0.07)\end{array}$ & $\ldots$ & 0.26 \\
\hline & $\begin{array}{c}0.48 \\
(0.11)\end{array}$ & $\begin{array}{c}0.04 \\
(0.12)\end{array}$ & $\begin{array}{c}0.11 \\
(0.12)\end{array}$ & $\begin{array}{c}0.16 \\
(0.12)\end{array}$ & $\begin{array}{c}0.63 \\
(0.35)\end{array}$ & $\begin{array}{c}-0.71 \\
(0.28)\end{array}$ & 0.31 \\
\hline \multirow[t]{2}{*}{ Mining } & $\begin{array}{c}0.20 \\
(0.12)\end{array}$ & $\begin{array}{r}-0.07 \\
(0.12)\end{array}$ & $\begin{array}{c}0.14 \\
(0.12)\end{array}$ & $\begin{array}{r}-0.14 \\
(0.12)\end{array}$ & $\begin{array}{r}-0.06 \\
(0.07)\end{array}$ & $\ldots$ & 0.01 \\
\hline & $\begin{array}{c}0.24 \\
(0.12)\end{array}$ & $\begin{array}{r}-0.02 \\
(0.12)\end{array}$ & $\begin{array}{c}0.19 \\
(0.12)\end{array}$ & $\begin{array}{r}-0.08 \\
(0.12)\end{array}$ & $\begin{array}{r}-0.00 \\
(0.07)\end{array}$ & $\begin{array}{c}-0.16 \\
(0.07)\end{array}$ & 0.06 \\
\hline \multirow[t]{2}{*}{ Primary metals } & $\begin{array}{c}0.16 \\
(0.12)\end{array}$ & $\begin{array}{c}0.07 \\
(0.12)\end{array}$ & $\begin{array}{c}0.05 \\
(0.12)\end{array}$ & $\begin{array}{c}0.11 \\
(0.12)\end{array}$ & $\begin{array}{r}-0.22 \\
(0.10)\end{array}$ & $\ldots$ & 0.01 \\
\hline & $\begin{array}{c}0.21 \\
(0.12)\end{array}$ & $\begin{array}{c}0.12 \\
(0.12)\end{array}$ & $\begin{array}{c}0.10 \\
(0.12)\end{array}$ & $\begin{array}{c}0.16 \\
(0.12)\end{array}$ & $\begin{array}{c}0.07 \\
(0.16)\end{array}$ & $\begin{array}{c}-0.31 \\
(0.14)\end{array}$ & 0.06 \\
\hline \multirow[t]{2}{*}{ Paper } & $\begin{array}{c}0.31 \\
(0.13)\end{array}$ & $\begin{array}{c}0.06 \\
(0.12)\end{array}$ & $\begin{array}{c}-0.14 \\
(0.12)\end{array}$ & $\begin{array}{c}0.15 \\
(0.12)\end{array}$ & $\begin{array}{r}-0.25 \\
(0.10)\end{array}$ & $\ldots$ & 0.11 \\
\hline & $\begin{array}{c}0.33 \\
(0.12)\end{array}$ & $\begin{array}{c}0.09 \\
(0.12)\end{array}$ & $\begin{array}{c}-0.12 \\
(0.12)\end{array}$ & $\begin{array}{c}0.16 \\
(0.12)\end{array}$ & $\begin{array}{c}0.15 \\
(0.22)\end{array}$ & $\begin{array}{r}-0.40 \\
(0.19)\end{array}$ & 0.15 \\
\hline \multirow[t]{2}{*}{ Motor vehicles } & $\begin{array}{c}0.25 \\
(0.12)\end{array}$ & $\begin{array}{r}-0.08 \\
(0.12)\end{array}$ & $\begin{array}{c}0.22 \\
(0.12)\end{array}$ & $\begin{array}{c}0.00 \\
(0.12)\end{array}$ & $\begin{array}{r}-0.20 \\
(0.09)\end{array}$ & $\ldots$ & 0.06 \\
\hline & $\begin{array}{c}0.23 \\
(0.12)\end{array}$ & $\begin{array}{r}-0.09 \\
(0.12)\end{array}$ & $\begin{array}{c}0.20 \\
(0.12)\end{array}$ & $\begin{array}{r}-0.01 \\
(0.12)\end{array}$ & $\begin{array}{c}0.33 \\
(0.31)\end{array}$ & $\begin{array}{r}-0.38 \\
(0.21)\end{array}$ & 0.09 \\
\hline \multirow[t]{2}{*}{ Petroleum } & $\begin{array}{r}-0.26 \\
(0.13)\end{array}$ & $\begin{array}{r}-0.16 \\
(0.14)\end{array}$ & $\begin{array}{l}0.10 \\
(0.14)\end{array}$ & $\begin{array}{c}0.15 \\
(0.13)\end{array}$ & $\begin{array}{c}0.02 \\
(0.06)\end{array}$ & $\ldots$ & 0.04 \\
\hline & $\begin{array}{r}-0.24 \\
(0.13)\end{array}$ & $\begin{array}{c}-0.15 \\
(0.14)\end{array}$ & $\begin{array}{l}0.11 \\
(0.14)\end{array}$ & $\begin{array}{c}0.16 \\
(0.13)\end{array}$ & $\begin{array}{c}0.05 \\
(0.06)\end{array}$ & $\begin{array}{c}-0.11 \\
(0.05)\end{array}$ & 0.08 \\
\hline \multirow[t]{2}{*}{ Chemicals } & $\begin{array}{c}0.23 \\
(0.13)\end{array}$ & $\begin{array}{c}0.14 \\
(0.12)\end{array}$ & $\begin{array}{c}-0.21 \\
(0.12)\end{array}$ & $\begin{array}{c}0.10 \\
(0.13)\end{array}$ & $\begin{array}{c}-0.13 \\
(0.09)\end{array}$ & $\ldots$ & 0.06 \\
\hline & $\begin{array}{c}0.24 \\
(0.12)\end{array}$ & $\begin{array}{c}0.16 \\
(0.12)\end{array}$ & $\begin{array}{c}-0.19 \\
(0.12)\end{array}$ & $\begin{array}{c}0.10 \\
(0.13)\end{array}$ & $\begin{array}{c}0.03 \\
(0.11)\end{array}$ & $\begin{array}{c}-0.18 \\
(0.09)\end{array}$ & 0.11 \\
\hline \multirow[t]{2}{*}{$\begin{array}{l}\text { Manufacturing } \\
\quad(\text { extended period })^{c}\end{array}$} & $\begin{array}{c}0.40 \\
(0.08)\end{array}$ & $\begin{array}{c}0.02 \\
(0.09)\end{array}$ & $\begin{array}{c}0.11 \\
(0.09)\end{array}$ & $\begin{array}{r}-0.15 \\
(0.08)\end{array}$ & $\begin{array}{r}-0.12 \\
(0.05)\end{array}$ & $\ldots$ & 0.18 \\
\hline & $\begin{array}{c}0.40 \\
(0.08)\end{array}$ & $\begin{array}{c}0.02 \\
(0.09)\end{array}$ & $\begin{array}{c}0.11 \\
(0.09)\end{array}$ & $\begin{array}{r}-0.15 \\
(0.08)\end{array}$ & $\begin{array}{r}-0.06 \\
(0.07)\end{array}$ & $\begin{array}{r}-0.06 \\
(0.04)\end{array}$ & 0.19 \\
\hline
\end{tabular}

a. Sample period is quarterly, 1970:2-1988:4, where quarterly observations are taken to be the last monthly observation in the quarter. Numbers in parentheses are standard errors. Dependent variable for each industry is the change in the natural $\log$ of $I P$.

b. Detrended is the residual from regressing $\log I P$ on a constant and linear time trend.

c. Sample period 1951:2-1988:4.

\section{Nonlinearity in the Relationship between Production and Capacity Utilization}

Capacity is best thought of as the level of output where the marginal cost curve becomes steep. If this region of the cost curve is sometimes relevant, the relationship between capacity and output should be non- 
linear. If capacity is tight, growth in capacity limits growth in output. If such nonlinearities are important, as surely they are if capacity is ever a binding constraint, then the linear-in-variables regressions presented above are likely to have little power to detect a role for capacity utilization in forecasting output.

I do not propose to develop a particular parametric model to detect nonlinearities in the relationship between output and capacity. Such results could be driven substantially by the parametric specification. Instead, I present a nonparametric analysis of how output changes respond to the level of capacity utilization. The outcome will suggest what parametric approaches, if any, seem promising.

How should high capacity utilization affect the distribution of production growth? On average, output grows at the same rate as capacity. At high utilization, output can grow no faster than capacity, but it could grow less fast. Therefore, at high utilization the growth rate of production should be below average. ${ }^{35}$ Insofar as high utilization implies a constraint on growth, the distribution of growth rates should be truncated to the right and skewed left at high levels of utilization. This truncation will potentially reduce the variance of output growth. Capacity constraints, if they are important, reduce the variance of output growth by attenuating upward blips in production.

To study the distribution of production growth conditional on the level of capacity I estimate a univariate, eighth-order autoregression of industrial production growth,

$$
\Delta \log I P_{t}=\alpha+\sum_{i=1}^{8} \beta_{i} \Delta \log I P_{t-i}+\epsilon_{t},
$$

to isolate the production surprise $\epsilon_{t}$. Here the log-differenced specification is clearly superior to specification in levels with a deterministic trend because it avoids the spurious mean reversion that arises in such specifications. ${ }^{36}$ As discussed earlier, except for the aggregate manufacturing data, the lagged variables have negligible explanatory power, so the output surprise $\epsilon_{t}$ is close to the growth rate itself; the serial correlation present in the growth rates is mainly positive. The constant term in equation 2 removes a stochastic trend from production.

35. High utilization at the industry level does not necessarily imply high utilization for all firms in that industry. Characterizations of the distributions should, however, apply on average in an industry.

36. See Nelson and Kang (1981). 
The hypothesis that capacity utilization matters for the forecast of output is investigated by asking whether the distribution of the production surprises $\epsilon_{t}$ is skewed to the left or truncated on the right conditional on high levels of utilization. Estimates of the distributions are presented in figure 2, which is constructed as follows. First, the production surprises are estimated by fitting equation 2. Second, quarters are classified as having either low capacity utilization or high capacity utilization. In the figure, the high-utilization quarters have utilization greater than the seventy-fifth percentile value. Low-utilization quarters are those on the twenty-fifth percentile. ${ }^{37}$ Third, smoothed empirical distributions of the production surprises for the two states of capacity utilization are reported in the figure. The choice of how many observations to include in the high- and low-utilization subsamples is based on a trade-off between selecting extreme observations and retaining sufficient degrees of freedom to provide a reasonably accurate estimate of the distribution. ${ }^{38}$ In general, many degrees of freedom are necessary to estimate a function, such as a distribution function. Therefore, the estimated distributions should be taken as convenient summaries of the data rather than as very precise estimates of the underlying distributions.

The smoothed empirical distributions are calculated by applying a normal kernel to the raw empirical distribution of the production surprises. This procedure treats each observation as a normal distribution with mean equal to the value of the observation and a fixed standard deviation. The smoothed empirical distribution is just the average of these distributions. ${ }^{39}$ Let $\epsilon=\left(\epsilon_{1}, \ldots, \epsilon_{N}\right)$ be a sample of $N$ surprises. The estimated height of the densities at each point $\epsilon_{i}$ plotted in the figure is given by

$$
f\left(\epsilon_{i}\right)=\frac{1}{N \omega} \sum_{j=1}^{N} \phi\left(\frac{\epsilon_{j}-\epsilon_{i}}{\omega}\right),
$$

where $\phi(\cdot)$ is the standard normal density and $\omega$ is a parameter governing the effective band over which the data are smoothed. Here, $\omega$ is set to the standard deviation of the sample $\epsilon$ divided by $N^{1 / 5}$.

37. The robustness of this classification scheme is investigated below.

38. There are 21 or 22 data points in each of the subsamples.

39. See Silverman (1986). I am grateful to Vassilis Hajivassiliou for making his kernel estimation program available to me. 
Figure 2 presents the estimated distributions. The units of the horizontal axes are the percentage change of the level of production (not at annual rate); the units of the vertical axes are probabilities. Examination of figure 2 leads to the following general characterizations of the distributions. First, the distribution of the production surprises is not shifted to the left in states of high utilization. Second, the distributions of the production surprises of the high-utilization state are close to symmetrical. They do not appear to be truncated on the right or skewed left as one would expect were they capturing a capacity ceiling neglected from the linear univariate time series model, equation 2. And, finally, the distributions of the low-utilization states have higher variances than those of the high-utilization state. They have thicker tails than the highutilization distribution both to the right and to the left. The distribution of output surprises appears to shrink symmetrically in states of high utilization. The distributions provide little evidence of an assymmetry in states of high capacity utilization that would indicate a wall or other barrier to further output expansion. The low-utilization distributions tend to have greater tails to the right, but they also have greater tails to the left. There thus appears to be more uncertainty at low levels of utilization. These nonparametric results argue against looking for asymmetries from capacity constraints in the context of a particular, parametric model. ${ }^{40}$

Perhaps the most striking feature of the difference between the distributions of production surprises at high and low levels of utilization is the difference in the variance. At high levels of utilization, there is much less variability in output than at low levels. This finding is not easily reconciled with any simple model of output fluctuations. If high utilization meant that output demand were constrained by a steep supply curve, high utilization would imply low variance in output, but it would also imply a lower mean.

The low variance at high utilization could be explained by a more elaborate model that includes backlogged orders. At high utilization, demand surprises might be truncated upward by the capacity constraint and truncated downward by the existence of a cumulated backlog of

40. Other researchers have looked for asymmetry in the business cycle. See Sichel (1989) and De Long and Summers (1988). De Long and Summers find much less asymmetry in unemployment rates after World War II than before. 

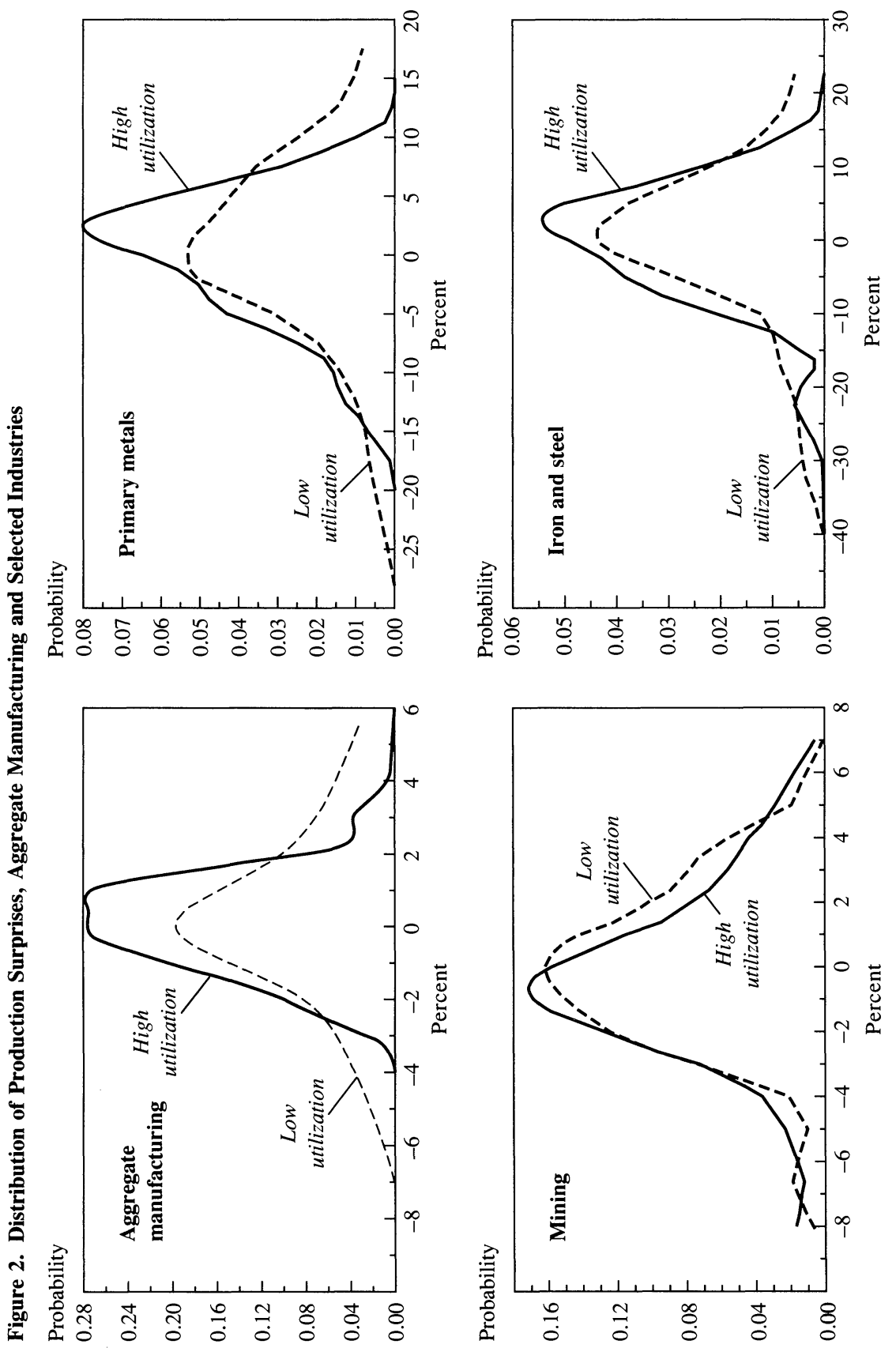

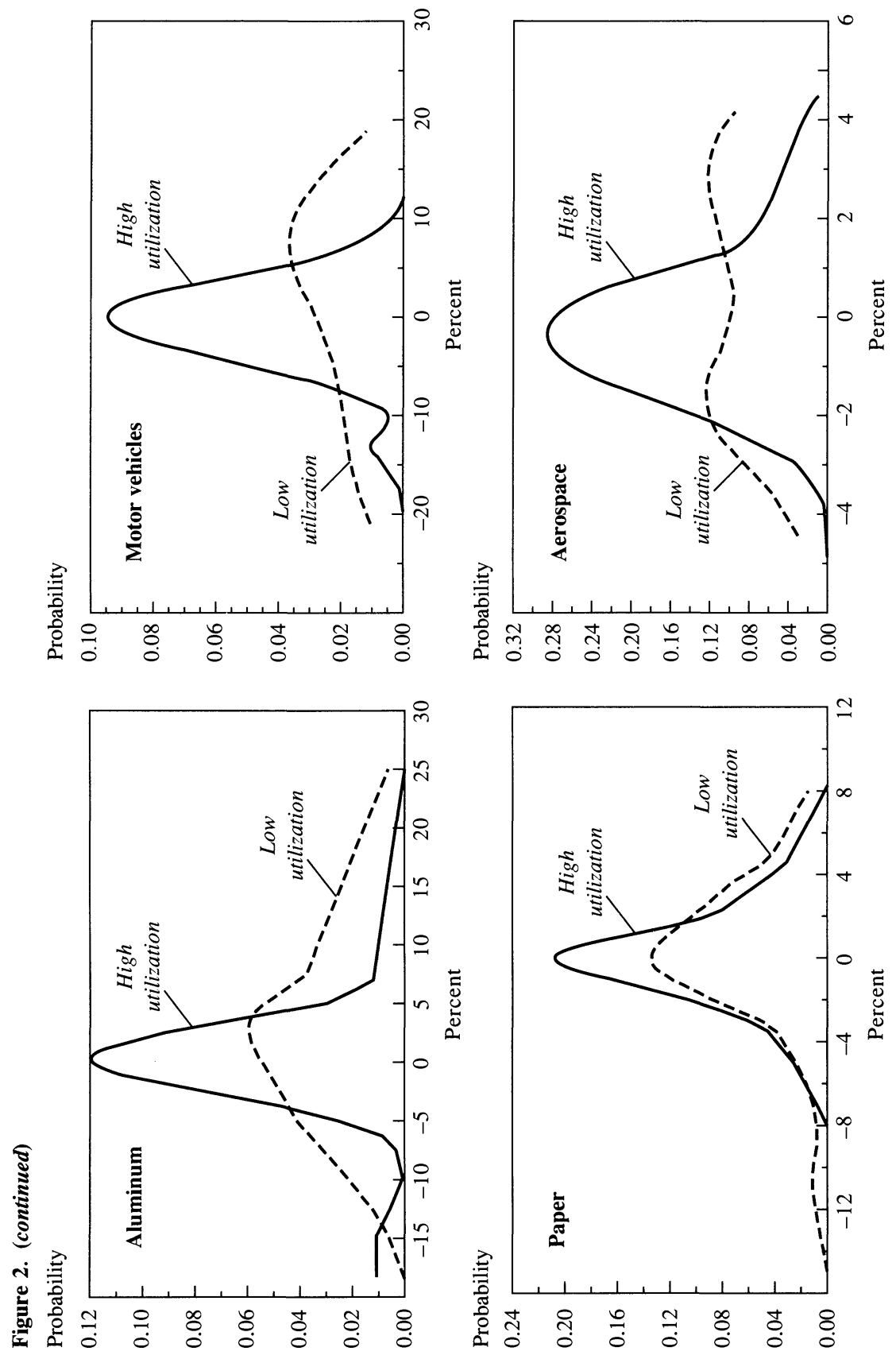

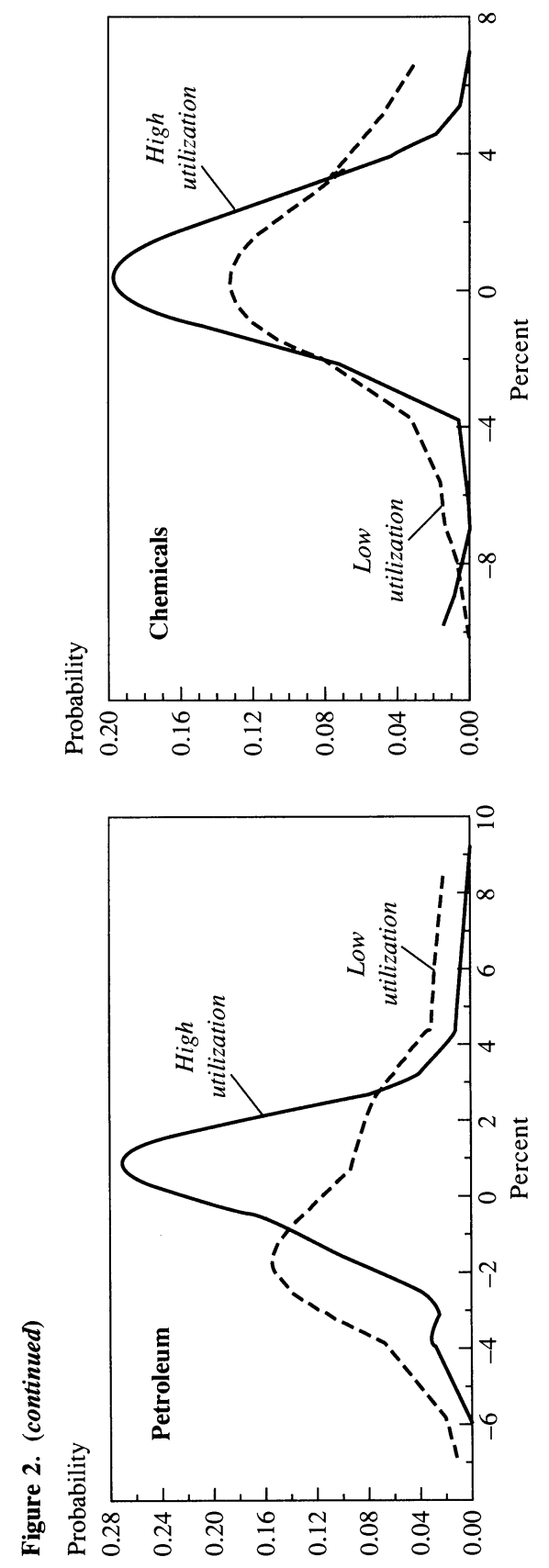
orders. Under this view, the production smoothing model of inventories is operative at high levels of utilization. While this explanation of the findings is probably worth exploring further, it is undermined by the finding that in states of high demand, inventory accumulation is particularly high. ${ }^{41}$ Some direct evidence concerning utilization and backlogs is presented below.

The distributions for the industries have some interesting individual features. The distributions for mining are similar for high and low utilization. In primary metals, the modal growth rate is higher for the high-utilization state; moreover, the low-utilization distribution has a thick tail to the left. The high-utilization distribution for primary metals does suggest some of the asymmetry one would expect from capacity constraints. It is steeper (in absolute value) on the right than on the left. This asymmetry is, however, much less apparent in the iron and steel and aluminum subindustries. In aluminum, the low variance at high utilization is particularly striking. Similarly to primary metals, paper is skewed left in the low-utilization state. At high utilization, the variance is again low, but no asymmetry is apparent. In the motor vehicles and aerospace industries, the greater variance in the low-utilization state is most dramatic. In petroleum, the slope of the low-utilization distribution is much less steep on the right side of the mode than on the left. Chemicals have the typical tight symmetric distribution for high utilization. Both the high- and low-utilization distributions share a long left tail..$^{42}$

\section{Sample Moments of Production Surprises by Level of Utilization}

The analysis of the previous section provides a rich characterization of the distribution of production surprises stratified by the level of capacity utilization. This section provides more conventional sample statistics for various subsamples of production surprises selected by the level of utilization. In addition to the top and bottom 25 percent stratification used in figure 2 , table 5 presents statistics for production surprises for the quarters with the top and bottom 10 and 50 percent of

41. Ramey (1988) finds that in booms driven especially by government purchases, both production and inventory accumulation are high.

42. Recall that the chemicals data are based on a mixture of physical and imputed data, so these results should probably be discounted. 
Table 5. Characteristics of the Distribution of Production Surprises Stratified by Level of Utilization ${ }^{\text {a }}$

\begin{tabular}{|c|c|c|c|c|c|c|c|}
\hline \multirow[b]{2}{*}{ Industry and moment ${ }^{\mathrm{b}}$} & \multicolumn{7}{|c|}{ Percentile of capacity utilization } \\
\hline & High 10 & Low 10 & High 25 & Low 25 & High 50 & Low 50 & All \\
\hline \multicolumn{8}{|l|}{ Manufacturing } \\
\hline Mean & -0.20 & 1.01 & -0.04 & 0.47 & -0.13 & 0.13 & 0.00 \\
\hline Standard deviation & 1.20 & $2.36^{c}$ & 1.32 & $2.33^{\mathrm{d}}$ & 2.02 & 1.95 & 1.98 \\
\hline Skewedness & -0.21 & -0.36 & 0.17 & 0.43 & -2.14 & 0.38 & -0.94 \\
\hline$s$ & -0.36 & -0.04 & -0.11 & 0.16 & -0.19 & 0.00 & -0.09 \\
\hline \multicolumn{8}{|l|}{ Mining } \\
\hline Mean & -0.29 & 0.05 & -0.38 & -0.05 & -0.46 & $0.47^{\mathrm{c}}$ & 0.00 \\
\hline Standard deviation & 1.95 & 1.79 & 2.76 & 2.38 & 2.55 & 2.53 & 2.57 \\
\hline Skewedness & 0.51 & 0.82 & -0.75 & -0.72 & -1.00 & -0.06 & -0.51 \\
\hline$s$ & 0.49 & 0.16 & -0.06 & 0.00 & -0.02 & -0.06 & -0.16 \\
\hline \multicolumn{8}{|l|}{ Primary metals } \\
\hline Mean & -0.66 & 1.69 & -0.41 & 1.21 & -1.16 & 1.19 & 0.00 \\
\hline Standard deviation & 5.51 & $11.65^{\mathrm{c}}$ & 5.33 & 8.35 & 6.86 & 7.21 & 7.09 \\
\hline Skewedness & -0.41 & -0.27 & -0.76 & -0.17 & -1.66 & -0.48 & -0.95 \\
\hline$s$ & -0.34 & 0.09 & -0.29 & 0.09 & -0.29 & -0.05 & -0.15 \\
\hline \multicolumn{8}{|l|}{ Iron and steel } \\
\hline Mean & -0.59 & -1.81 & 0.00 & -0.06 & -1.54 & 1.57 & 0.00 \\
\hline Standard deviation & 6.44 & 14.29 & 7.41 & 11.47 & 9.94 & 9.54 & 9.81 \\
\hline Skewedness & 0.40 & -0.85 & -1.01 & -0.48 & -1.65 & -0.75 & -1.19 \\
\hline$s$ & 0.42 & -0.15 & -0.20 & -0.04 & -0.27 & -0.02 & -0.17 \\
\hline \multicolumn{8}{|l|}{ Aluminum } \\
\hline Mean & 0.27 & -0.22 & -1.10 & 0.87 & -0.01 & 0.01 & 0.00 \\
\hline Standard deviation & 1.77 & $5.99^{\mathrm{d}}$ & 5.42 & 7.60 & 4.38 & 6.21 & 5.31 \\
\hline Skewedness & 0.02 & -0.13 & -2.30 & 1.42 & -2.47 & 1.42 & 0.36 \\
\hline$s$ & 0.11 & 0.25 & -0.18 & -0.01 & -0.13 & -0.11 & -0.13 \\
\hline \multicolumn{8}{|l|}{ Paper } \\
\hline Mean & -0.54 & 0.42 & 0.05 & 0.28 & -0.26 & 0.28 & 0.00 \\
\hline Standard deviation & 1.14 & $5.46^{\mathrm{c}}$ & 2.25 & 3.80 & 2.92 & 3.20 & 3.05 \\
\hline Skewedness & -1.23 & -0.88 & -0.10 & -0.91 & -2.62 & -1.10 & -1.71 \\
\hline$s$ & -0.28 & -0.03 & 0.02 & 0.02 & -0.08 & 0.08 & -0.01 \\
\hline
\end{tabular}

the level of capacity utilization. The last column gives the statistics for the entire sample.

Table 5 presents the means, standard deviations, and skewedness for the various subsamples. The skewedness should be interpreted with caution because not all asymmetric distributions have nonzero skewedness. ${ }^{43}$ The statistic $s$, equal to the difference between the mean and median divided by the standard deviation, is presented as another

43. The skewedness of a distribution may provide little information about its asymmetry. A highly asymmetric distribution can have a zero third moment; a distribution that is truncated on the right might also be skewed right. See Mood, Graybill, and Boes (1974, pp. 75-76); also Kendall and Stuart (1977, pp. 87-88). 
Table 5. (continued)

\begin{tabular}{|c|c|c|c|c|c|c|c|}
\hline \multirow[b]{2}{*}{ Industry and moment ${ }^{\mathrm{b}}$} & \multicolumn{7}{|c|}{ Percentile of capacity utilization } \\
\hline & High 10 & Low 10 & High 25 & Low 25 & High 50 & Low 50 & All \\
\hline \multicolumn{8}{|l|}{ Motor vehicles } \\
\hline Mean & -1.14 & 3.16 & -1.08 & 0.73 & -1.34 & 1.37 & 0.00 \\
\hline Standard deviation & 3.30 & $8.86^{d}$ & 4.44 & $10.62^{\mathrm{d}}$ & 5.95 & $9.00^{\mathrm{d}}$ & 7.69 \\
\hline Skewedness & -0.50 & -0.44 & -0.85 & -0.59 & -1.18 & -0.62 & -0.54 \\
\hline$s$ & -0.05 & -0.21 & -0.05 & -0.27 & -0.19 & -0.06 & -0.13 \\
\hline \multicolumn{8}{|l|}{ Aerospace } \\
\hline Mean & -0.19 & $1.68^{\mathrm{c}}$ & -0.08 & 0.61 & -0.10 & 0.11 & 0.00 \\
\hline Standard deviation & 1.64 & 2.25 & 1.45 & $2.51^{\mathrm{d}}$ & 1.77 & 2.15 & 1.96 \\
\hline Skewedness & 1.68 & -0.38 & 0.75 & -0.09 & -0.17 & 0.15 & 0.07 \\
\hline$s$ & 0.21 & 0.07 & 0.18 & -0.05 & -0.07 & 0.05 & -0.02 \\
\hline \multicolumn{8}{|l|}{ Petroleum } \\
\hline Mean & -0.41 & 0.54 & 0.31 & -0.39 & 0.16 & -0.16 & 0.00 \\
\hline Standard deviation & 2.11 & 3.83 & 1.61 & 3.14 & 2.30 & 2.91 & 2.61 \\
\hline Skewedness & 0.15 & 1.76 & -0.77 & 1.32 & -0.66 & 0.56 & 0.10 \\
\hline$s$ & -0.02 & 0.41 & -0.10 & 0.29 & -0.13 & 0.06 & -0.07 \\
\hline \multicolumn{8}{|l|}{ Chemicals } \\
\hline Mean & -1.30 & 1.02 & -0.10 & 0.22 & -0.01 & 0.01 & 0.00 \\
\hline Standard deviation & 3.56 & 3.53 & 2.67 & 3.42 & 2.08 & 3.00 & 2.56 \\
\hline Skewedness & -2.23 & 0.85 & -2.59 & -0.21 & -2.69 & -0.54 & -1.11 \\
\hline$s$ & -0.19 & 0.40 & -0.07 & 0.04 & -0.09 & 0.05 & -0.07 \\
\hline \multicolumn{8}{|c|}{ Manufacturing (extended period)e } \\
\hline Mean & -0.37 & $1.22^{\mathrm{d}}$ & -0.16 & 0.25 & -0.26 & 0.28 & 0.00 \\
\hline Standard deviation & 1.64 & $2.44^{\mathrm{c}}$ & 1.41 & $2.78^{\mathrm{d}}$ & 2.14 & 2.49 & 2.33 \\
\hline Skewedness & -0.40 & -0.75 & -0.48 & -0.07 & -1.88 & $0.56^{c}$ & -0.36 \\
\hline$s$ & -0.20 & -0.41 & -0.16 & -0.07 & -0.23 & 0.08 & -0.07 \\
\hline
\end{tabular}

a. Sample is quarterly from 1967:1 through 1988:4.

b. Statistic $s=$ (mean - median)/standard deviation.

c. Statistics for high and low subsamples statistically different at the 10 percent level.

d. Statistics for high and low subsamples statistically different at the 5 percent level.

e. Sample 1950:1-1988:4.

indicator of skewedness. Notes indicate whether the differences in the moments are statistically significant.$^{44}$ Note that few are, so the differences in table 5 (and figure 2) should not be overemphasized. Yet, many of the differences are similar across industries (especially in the case of the standard deviations), a consistency that indicates much stronger support for the characterization of the results than the tests within the industries.

44. The test statistics are based on $t$-statistics. The tests for the second moments are calculated based on the variances, not the standard deviations. The tests of equal variance allow the means to differ across the samples. The tests of equal third moment allow both the means and the variances to differ. No statistical inference is undertaken with the statistic $s$. 
The growth surprises are generally lower in the high-utilization state than in the low-utilization state. Although this finding provides some support that high measured capacity utilization does constrain output growth, the evidence is weak on several counts. First, the differences are rarely statistically significant from each other. Second, the differences in the growth rates arise more because the growth rate surprises are on average positive at low utilization than because they are on average negative at high utilization. The low-utilization states are more unusual than the high-utilization ones, whereas theories of capacity constraints highlight unusual behavior at the peak. Third, the data are constructed by the Federal Reserve under the model that high capacity utilization does represent a ceiling on output, so the data construction builds in some mean reversion by keeping capacity from drifting away from production. Thus, it is all the more striking that no pattern of significant mean reversion appears. Finally, there is a small sample bias towards finding mean reversion. High-utilization states are necessarily followed by periods of lower utilization. These transitions from high to lower utilization contribute to finding lower mean growth rates at high utilization regardless of whether capacity ceilings exist.

The standard deviations of the growth surprises reported in table 5 confirm the hypothesis about the way variance of growth surprises would reflect a limit on capacity. The variability is smaller at higher levels of utilization in most industries, although, again, the differences are usually not statistically significant.

Finally, the measures of skewedness show the distributions skewed left most of the time for all levels of utilization. Again, the differences are not statistically significant across distributions, but the high-utilization distributions are usually more skewed than the low-utilization ones.

\section{Capacity Utilization and Real Activity: Additional Tests}

If capacity were truly a binding constraint, other real activity variables besides production should react to its high shadow value. Specifically, deliveries might lag and unfilled orders accumulate. Capacity should also expand. In this section I focus on these relationships. 


\section{Vendor Performance and Unfilled Orders}

The time series on vendor performance provides an alternative indicator conveying the relationship of output to capacity. To test whether high utilization makes it harder for vendors to satisfy increases in demand, I consider a regression of vendor performance $(V)$, the percentage of respondents reporting slower deliveries, on current and lagged capacity utilization in aggregate manufacturing $(C U)$ as well as its own lags. For quarterly data from 1959 through the first half of 1988, the estimated equation is

$$
\begin{aligned}
V_{t}= & -0.07+0.71 V_{t-1}-0.04 V_{t-2}-0.07 V_{t-3} \\
(0.10)(0.12) & (0.12) \\
& +0.03 V_{t-4}+2.12 C U_{t}-1.49 C U_{t-1} \\
& (0.10) \quad(0.45) \quad(0.67) \\
& +0.16 C U_{t-2}-0.27 C U_{t-3}-0.18 C U_{t-4}+\epsilon_{t} \\
& (0.69) \quad(0.68)
\end{aligned}
$$

Standard error of estimate $=\mathbf{0 . 0 7 8}$,

where standard errors are shown in parentheses. The vendor performance and $C U$ data both refer to the last month of the quarter. The coefficient of current capacity utilization is positive and strongly significant. The first lag is negative and also significant. ${ }^{45}$ That pattern of coefficients suggests that the relationship is between the change in $C U$ and vendor performance. (Vendor performance itself is expressed as a change from the previous month in the survey.) Therefore, vendor performance and capacity utilization do move consistently with the hypothesis that high utilization makes it harder to satisfy demand.

While vendor performance provides some survey evidence from the supply side about tightness and bottlenecks, unfilled orders provide a direct measure. Consider a regression of the ratio of unfilled orders to shipments $(U O)$ on lags of itself and on current and lagged capacity utilization. The equation estimated with quarterly data from 1959 through the first half of 1988 for aggregate manufacturing is

45. The coefficients of capacity utilization are strongly jointly significant. 
(5)

$$
\begin{aligned}
U O_{t}= & -0.09+0.94 U O_{t-1}+0.29 U O_{t-2}-0.15 U O_{t-3} \\
(0.10) & (0.14) \quad(0.14) \\
& -0.12 U O_{t-4}-2.31 C U_{t}+3.08 C U_{t-1} \\
& (0.10) \quad(0.47) \quad(0.82) \\
& +1.11 C U_{t-2}-1.57 C U_{t-3}-0.03 C U_{t-4}+\epsilon_{t}
\end{aligned}
$$

Standard error of estimate $=0.083$.

The impact of current utilization on order backlogs has a perverse, negative sign. The predicted effect occurs only with a lag and is offset somewhat by subsequent lags. Yet the cumulative effect of increase in capacity utilization on unfilled orders is positive. Moreover, the lagged values of capacity utilization are jointly significant. ${ }^{46}$ Therefore, capacity utilization does appear to predict aggregate unfilled orders, though the timing is unsatisfactory for a simple link between the two.

I also consider estimates of the same equation for one additional industry, the primary metals sector. Capacity constraints figure in the anecdotal discussions of this industry. These estimates are of particular interest because of both the relatively high quality and the homogeneity of the data and because in figure 2 for primary metals there was some weak evidence of a capacity constraint. Over the sample from 1968 through the first half of 1988 , the estimates are

$$
\begin{aligned}
U O_{t}= & 0.17+0.64 U O_{t-1}+0.28 U O_{t-2}+0.01 U O_{t-3} \\
(0.12) & (0.15) \\
- & 0.07 U O_{t-4}-0.21 C U_{t}+0.44 C U_{t-1} \\
& (0.12) \quad(0.35) \quad(0.50) \\
& +0.29 C U_{t-2}-0.30 C U_{t-3}-0.02 C U_{t-4}+\epsilon_{t}, \\
& (0.50)
\end{aligned}
$$

Standard error of estimate $=0.166$.

Unlike in the aggregate, the effect of utilization on the forecast of unfilled orders in primary metals is weak. Again, the impact effect is negative. Moreover, the coefficients are statistically insignificant. ${ }^{47}$

46. The $F(5,108)$ test is 10.9 , which has marginal significance $<0.001$.

47. The $F(4,73)$ of 0.90 has marginal significance 0.47 . 


\section{Investment}

The final link between real activity and utilization I examine is that with capital accumulation. If high measured capacity utilization indicates that capacity is tight, capacity utilization should forecast investment. Firms should respond to a high shadow value of the capacity constraint by relaxing it via capital accumulation. ${ }^{48}$

Table 6 presents estimates of an equation to evaluate whether capacity utilization helps forecast investment. The investment rate $(I / K)$ is regressed on the lagged output-capital $(I P / K)$ and output-capacity $(C U)$ ratios to evaluate how utilization affects the forecast of investment. A lagged dependent variable is also included. These equations must be interpreted as forecasting equations rather than structural demand for capital equations. The industry-level capital and investment data are available on an annual (year-end to year-end) basis; only one lag is allowed.

For aggregate manufacturing, the capacity utilization rate does dominate the output-capital ratio in the regressions reported in table 6 . The coefficient of the utilization rate is strongly positive, whereas the coefficient of the output-capital ratio is small and insignificant. The interpretation of this finding as evidence that the observed business fixed investment is moving to relax capacity constraints as measured by the Federal Reserve utilization rates is undermined, however, by the disaggregated estimates. In all the industries reported in table 6 except chemicals, the utilization rate has the wrong sign while the coefficient of the output-capital ratio is large, positive, and usually significant. Thus, output relative to capacity does matter for investment demand. However, these estimates suggest that - in formulating investment demandthe BEA's capital stock is a better indicator of capacity than is the Federal Reserve's capacity measure.

\section{Utilization and Prices}

Earlier I have examined the distribution of production changes as a function of the level of measured capacity utilization. High measured

48. The link between capacity utilization and capital accumulation is also important because the endogenous relaxation of the utilization constraint might well account for the failure of output surprise to be truncated when utilization is high. 
Table 6. Investment Rates and Capacity Utilization ${ }^{\mathrm{a}}$

\begin{tabular}{lcccc}
\hline \multicolumn{1}{c}{ Industry } & $\log$ & $\log$ & $\log$ & $\begin{array}{c}\text { Standard } \\
\text { error of } \\
\text { estimate }\end{array}$ \\
\hline Manufacturing & $(I / K)_{(-1)}$ & $(I P / K)_{(-1)}$ & $C U_{(-1)}$ & 0.045 \\
Mining & 0.21 & -0.31 & 1.48 & $0.0 .58)$ \\
Primary metals & $(0.12)$ & $(0.53)$ & $(0.58)$ & \\
& 1.13 & 0.58 & -0.04 & 0.113 \\
Paper & $(0.22)$ & $(0.37)$ & $(0.85)$ & \\
& 0.56 & 0.79 & -0.26 & 0.102 \\
Motor vehicles & $(0.12)$ & $(0.62)$ & $(0.70)$ & \\
& 0.67 & 1.48 & -0.92 & 0.091 \\
Petroleum & $(0.16)$ & $(0.50)$ & $(0.63)$ & \\
& 0.53 & 0.97 & -0.06 & 0.199 \\
Chemicals & $(0.17)$ & $(0.57)$ & $(0.63)$ & \\
& 0.59 & 2.20 & -2.95 & 0.161 \\
Manufacturing (extended & $(0.20)$ & $(0.52)$ & $(0.91)$ & \\
period) & 0.89 & 0.52 & 0.84 & 0.090 \\
\hline
\end{tabular}

a. The dependent variable for each industry is the log of the ratio of the investment rate to capital stock ( $I / K)$. Table reports the estimated regression coefficients of the lag logs of the dependent variable, the ratio of production to capital $(I P / K)$, and of $C U$. Numbers in parentheses are standard errors. Samples are annual from 1968 through 1986. The investment rates $\left(I_{t}\right)$ and capital stock $\left(K_{t}\right)$ are from the BEA capital data by industry. The capital stock refers to the end-of-year and is measured as the net stock in constant dollars. Industrial production and utilization are their December values.

b. Sample is 1949 through 1986.

capacity utilization does not appear to signal constraints on output growth. Here I examine the dual implication of a capacity constraint. That is, I look for evidence from price behavior that marginal cost increases with capacity utilization.

Identifying aggregate tight capacity with inflation is merely relabeling the Phillips curve relationship between unemployment or the output gap and inflation. This paper has little to add to the study of that well-known empirical regularity.

Discussions of capacity utilization and price change appear, however, to provide some microeconomic foundations for the response of price to high utilization. They emphasize two sorts of costs associated with high capacity utilization. The first, the cost of bottlenecks, increased wear and tear, and so on, is clearly associated with tight physical capacity. The second is increased labor costs, which arise from overtime and the 
extra cost of late shifts, and which might be incurred even if capital is not scarce. If limits on capacity per se do increase marginal cost, then prices should increase beyond the increase in wages arising from overtime or extra shifts.

In the estimates that follow, an attempt is made to control for components of marginal cost that might rise when output rises. The general wage level might rise as the economy goes up the aggregate labor supply curve. The industry wage rate might rise even with idiosyncratic increases in industry output if labor is not very mobile across sectors or if short-run marginal labor costs are increasing due to shift or overtime premiums.

To examine whether capacity utilization is priced above these increases in cost due to higher wages at higher levels of activity, I estimate a system of dynamic wage-price equations for aggregate manufacturing and the individual industries. ${ }^{49}$ Shocks to capacity utilization can clearly have arbitrary impacts on the price level, so these shocks in the price equation are left unrestricted. If capacity utilization shocks are, however, to be interpreted as demand shocks, capacity utilization shocks should not permanently affect the level of the real wage. This restriction is imposed by requiring that the sum of the coefficients of $C U$ in the pricewage equation (equation 7) equals zero and that shocks to $C U$ only temporarily affect its own level..$^{50}$ Additionally, oil shocks are included in the system of equations to be estimated to control explicitly for the major source of exogenous cost shock during the postwar sample.

The equations estimated are as follows:

$$
\begin{aligned}
\Delta \log P_{t}- & \Delta \log W_{t}=\alpha_{1}+\sum_{i=1}^{4} \beta_{i}^{11}\left(\Delta \log P_{t-i}-\Delta \log W_{t-i}\right) \\
& +\sum_{i=1}^{4} \beta_{i}^{12} \Delta \log P_{t-i}+\sum_{i=0}^{4} \beta_{i}^{13} C U_{t-i} \\
& +\sum_{i=0}^{4} \beta_{i}^{14} \Delta P \text { Oil }_{t-i}+u_{t}^{1},
\end{aligned}
$$

49. The econometric analysis applies to published producer price indexes. It therefore ignores nonprice changes in terms of trade, such as terms of delivery and financing, that could well change with capacity utilization. See Carlton (1986).

50. Also, capacity utilization must be modeled as a stationary process. This method for imposing identifying restrictions in a dynamic model is discussed in detail in Blanchard and Quah (1988) and Shapiro and Watson (1988). In the estimates reported here, the pricewage equation is estimated by ordinary least squares, so the shock to $C U$ should not be given a structural interpretation. 


$$
\begin{aligned}
\Delta \log P_{t}= & \alpha_{1}+\sum_{i=1}^{4} \beta_{i}^{21}\left(\Delta \log P_{t-i}-\Delta \log W_{t-i}\right) \\
& +\sum_{i=1}^{4} \beta_{i}^{22} \Delta \log P_{t-i}+\sum_{i=0}^{4} \beta_{i}^{23} C U_{t-i} \\
& +\sum_{i=0}^{4} \beta_{i}^{24} \Delta P O i l_{t-i}+u_{t}^{2}, \\
C U_{t}= & \alpha_{1}+\sum_{i=1}^{4} \beta_{i}^{31}\left(\Delta \log P_{t-i}-\Delta \log W_{t-i}\right) \\
& +\sum_{i=1}^{4} \beta_{i}^{32} \Delta \log P_{t-i}+\sum_{i=1}^{4} \beta_{i}^{33} C U_{t-i} \\
& +\sum_{i=0}^{4} \beta_{i}^{34} \Delta P \text { Oil }_{t-i}+u_{t}^{3},
\end{aligned}
$$

The system is a vector autoregression in the growth in prices, growth in wages, and the capacity utilization rate, with oil price growth $\triangle P O i l$ taken as exogenous. The wage rate is entered via a price-wage equation. ${ }^{51}$ Capacity utilization is entered contemporaneously in the price-wage and price equations and thus has a contemporaneous effect on these variables. It is difficult to give a structural interpretation to this estimation procedure because prices, wages, and capacity utilization are simultaneously determined. Therefore, the reported estimates should be thought of as a way of studying the partial correlation of utilization and pricewage ratio in a rich dynamic setting.

The results of estimating the system, by least squares, are reported in table 7. To summarize the role of measured capacity utilization in the equations, the impact of a shock to the capacity utilization equation is traced through the system. That is, the disturbance $u_{t}^{3}$ in equation 9 is perturbed, and its impact reflects the dynamics of the utilization equation. The first column gives the response of the price-wage margin to a shock in capacity utilization; the second column gives the response of the price level. Responses, calculated as elasticities (percentage response to a percentage point shock), are reported at one-quarter and one-year horizons. The marginal significance of a test that all the $C U$ coefficients are zero in the price-wage and price equations is also reported.

The results of the tests of the impact of capacity utilization on the wage-price margin are striking. Except for motor vehicles, capacity utilization does not have a significant impact on the margins in either the aggregate or industry equations. The hypothesis that the shadow price

51. Because the lags of $\Delta \log P$ and $\Delta \log P-\Delta \log W$ enter the equations without restriction, this system leads to results that are numerically equivalent to a system where the price-wage equation is replaced with a wage equation. 
Table 7. Multivariate Price-Wage Equations: Elasticities of Responses to Shock in Capacity Utilization ${ }^{\mathrm{a}}$

\begin{tabular}{|c|c|c|}
\hline \multirow[b]{2}{*}{ Industry } & \multicolumn{2}{|c|}{ Response } \\
\hline & $\begin{array}{l}\text { Price-wage } \\
\text { margin }\end{array}$ & Price \\
\hline \multicolumn{3}{|l|}{ Manufacturing } \\
\hline One quarter & 0.09 & 0.21 \\
\hline Four quarters & 0.08 & 0.11 \\
\hline Significance & 0.17 & $<0.01$ \\
\hline \multicolumn{3}{|l|}{ Primary metals } \\
\hline One quarter & 0.02 & 0.09 \\
\hline Four quarters & 0.03 & 0.07 \\
\hline Significance & 0.48 & 0.05 \\
\hline \multicolumn{3}{|l|}{ Paper } \\
\hline One quarter & 0.06 & 0.16 \\
\hline Four quarters & 0.20 & 0.27 \\
\hline Significance & 0.15 & $<0.01$ \\
\hline \multicolumn{3}{|l|}{ Motor vehicles } \\
\hline One quarter & -0.23 & -0.06 \\
\hline Four quarters & -0.02 & -0.05 \\
\hline Significance & $<0.01$ & 0.28 \\
\hline \multicolumn{3}{|l|}{ Petroleum } \\
\hline One quarter & 0.04 & 0.05 \\
\hline Four quarters & 0.34 & 0.30 \\
\hline Significance & 0.32 & 0.30 \\
\hline \multicolumn{3}{|l|}{ Chemicals } \\
\hline One quarter & 0.13 & 0.12 \\
\hline Four quarters & 0.01 & 0.11 \\
\hline Significance & 0.14 & 0.03 \\
\hline \multicolumn{3}{|c|}{ Manufacturing (extended period) ${ }^{\mathrm{b}}$} \\
\hline One quarter & -0.09 & 0.08 \\
\hline Four quarters & 0.07 & 0.09 \\
\hline Significance & 0.22 & 0.08 \\
\hline
\end{tabular}

a. Sample is quarterly from 1968:1 through 1988:4. Percentage response to a 1 percentage point shock in capacity utilization. Estimates are based on the system of equations (equations 7-10) described in the text. The first row under each industry gives the response of the price-wage margin in the first quarter, the second gives the response in the fourth quarter, and the third gives the marginal significance level of the test that all the coefficients of CU are zero in the price-wage and price equations.

b. Sample 1955:1 through 1988:4.

of capital does not increase with capacity utilization cannot be rejected. These results provide further evidence that high measured capacity utilization is not an indicator that capacity is tight at either the sectoral or industrial level.

The hypothesis tests should not be viewed in isolation from the point estimates. The failure to reject the hypothesis that the impact of utiliza- 
tion on margins is negligible could arise because the estimates are imprecise rather than because the estimated impact is small. But the point estimates also suggest that high measured capacity utilization does not cause margins to rise appreciably. The last line of table 7 reports the estimates for the full time series on aggregate manufacturing. (The sample begins in 1955 to exclude the Korean War price controls and their aftermath.) In the full sample of manufacturing, a shock to capacity utilization causes price-cost margins to fall. In motor vehicles, the only industry where the estimates are statistically significant, the margin falls sharply on impact of the shock. In the other industries as well as the short sample for manufacturing, the point estimates are positive, but usually small. Comparing the first and second columns shows that prices do rise when utilization is high, but not by much more than wages are increasing. Therefore, there is no evidence that tight capacity is priced.

The nominal price level is positively correlated with capacity utilization at both the aggregate and industry level. The results from the margin equation imply that this correlation should not be given a structural interpretation that depends on tight capacity. That is, high utilization of capacity is not responsible per se for the price increases.

These findings that high capacity utilization has a small, insignificant, and sometimes negative impact on prices (after controlling for wages) are consistent with earlier literature. George Perry estimates similar equations, with industry capacity utilization measured either by the McGraw-Hill index or the WEFA index. ${ }^{52}$ Controlling for the general price level by including a distributed lag of wages and materials price, Perry finds that utilization has a generally positive impact on the industry prices except in the food and motor vehicles industries. Aside from the difference in the sample, the results reported here probably differ because of the greater restrictions placed on the dynamics here. Kenneth Coutts, Wynne Godley, and William Nordhaus find a negative cumulative effect of utilization (output relative to a trend) on the price level (relative to a composite cost variable) in four of the seven British manufacturing industries they study. ${ }^{53}$ Where they find a positive effect, it is small. In their industry price equations, Otto Eckstein and David Wyss include capacity utilization in only eight of fifteen U.S. industries. ${ }^{54}$ These

52. Perry (1973, pp. 726-30).

53. Coutts, Godley, and Nordhaus (1988, p. 66).

54. Eckstein and Wyss (1972, pp. 137-38). 
coefficients are positive and significant. Their procedure was to drop insignificant variables, so their evidence also indicates that utilization does not matter for prices in many industries.

\section{Conclusion}

This paper offers several types of evidence useful for assessing the Federal Reserve's indexes of capacity and capacity utilization: the data construction procedures of the Federal Reserve; the relationship between capacity utilization and production; the relationship between utilization and other real variables-investment, vendor performance, and unfilled orders; and the relationship between capacity utilization and price change.

The discussion of the Federal Reserve's data construction procedures raises serious questions about how the data should be interpreted. For many industries, capacity is based on vague survey questions. Various data are combined by complicated regression, averaging, judgmental, and interpolation procedures. Because utilization and capacity are, to borrow the term from the Chairman of the Board of Governors, elusive concepts, it is difficult to evaluate the objective of the data construction procedures. The Federal Reserve procedure, moreover, mixes engineering and economic notions of capacity, particularly in its assumption that seasonal peaks in output are unsustainable.

The level of capacity utilization does not enter a forecasting equation for output given lags of output. Moreover, the distribution of output surprises conditional on measures of the level of capacity utilization does not have the shape one would expect if high capacity utilization really signaled constraints on the expansion of output. At high levels of utilization, the range of positive innovations in output is no more narrow than the range of negative innovations. There is, however, a shrinking of variance at the high levels of utilization, which could arise from an interaction of backlogged orders and capacity constraints. Although the preliminary evidence in this paper and of recent work on the outputinventory correlation is not supportive of that view, it bears further investigation. In any case, the lower variance of production surprises at higher utilization rates is an interesting finding.

Finally, relative prices or markups do not rise significantly with high 
capacity utilization. Indeed, for motor vehicles the point estimate suggests that they fall. The results for price behavior are therefore consistent with those for output behavior in showing little or no evidence of capital constraints raising costs. High capacity utilization does not signal that the economy is approaching a barrier that precludes further output expansion.

The finding that industries with high measured capacity utilization fail to behave as if they were constrained can be interpreted in two ways. The first interpretation is that the measures of capacity and utilization convey little additional information beyond other indicators of the state of the business cycle.

The second is to allow that measured capacity does correctly measure the level of output given a smoothed, historical level of capital, labor, and materials input, but to suggest that supply does not attenuate movements in demand at high levels of utilization. The present results are consistent with the idea that periods of high output (and high measured capacity utilization) are periods of low-cost, or at least not high-cost, production. In this case there would be no presumption that relative prices should increase in industries with high capacity utilization. That margins do not fall systematically with higher utilization seems to argue not for exogenous cost shocks, but that supply is very elastic.

Should one interpret the findings of this paper as implying that the demand-shock, supply-constraint model of capacity utilization is correct, but that the Federal Reserve is not successful at measuring capacity, or that the Federal Reserve's measurements might be capturing capacity, but that capacity is not a binding constraint? The results of the paper do not point strongly to either conclusion. I would, however, lean toward the latter on the grounds that the absence of the output-capacity link is found even in industries where the Federal Reserve, because it has physical data, is probably doing a good job of measuring capacity.

Finally, the findings of this paper suggest that the Federal Reserve should avoid giving a structural interpretation to high capacity utilization. High measured utilization does not imply that the economy has hit a barrier to further growth or that capital is scarce. Consequently, high measured utilization per se should not signal to the Federal Reserve that interest rates should be raised or that the growth rate of the money supply should be slowed. 


\section{APPENDIX}

THE DATA for this study are as described below.

Production, Utilization, and Capacity. The Federal Reserve Board's indexes of industrial production $(I P)$ and of capacity utilization $(C U)$ are published in the Federal Reserve's Industrial Production and various issues of the Federal Reserve Bulletin. Up-to-date data were obtained from the Federal Reserve's monthly statistical releases, Industrial Production and Capacity Utilization.

In the statistical analyses, quarterly observations are taken as the last month in the quarter and annual observations are taken as the December value. These data are all seasonally adjusted. In the regression, $C U$ is expressed as a fraction and growth rates as log-differences (not percentages).

To infer capacity $(C A P), I P$ is divided by $C U$.

Survey data on capacity utilization are taken from the Annual McGraw-Hill Survey of Business Plans for New Plants and Equipment (Lexington, Mass.: Data Resources, Inc.). The implied McGraw-Hill capacity figures are the Federal Reserve's IP divided by the McGrawHill utilization rate. The McGraw-Hill survey refers to December.

Capital Stock and Investment. The Bureau of Economic Analysis (BEA) now publishes capital stock and investment by industry on a constant dollar basis. The data used in this study were obtained from the BEA data tape. Recent data are published and discussed in the August 1987 Survey of Current Business and in the BEA's Fixed Tangible Wealth. The capital stock $(K)$ refers to the end-of-year constant dollar net stock. The investment $(I)$ is the corresponding gross flow.

Price and Wages. The Bureau of Labor Statistics's producer price index is used to measure the price level $(P)$. The PPIs are gross price indexes that most closely correspond to the two-digit industries. The BLS's average hourly earnings for production workers is used to measure wages $(W)$. The oil price is measured by the PPI for crude petroleum (PPI 561). 


\section{Comments and Discussion}

Robert J. Gordon: Matthew Shapiro has given us a paper that can be judged from either a narrow or broader perspective. At the narrow level of pure measurement, he argues effectively that the short-run movements of the Federal Reserve's capacity utilization index contain no information not already present in their index of industrial production and that the usefulness of the utilization index over a longer horizon is clouded by serious measurement and conceptual problems, particularly the illdefined questions posed in the surveys on which capacity estimates are based for many industries. From a broader perspective, however, Shapiro is unconvincing in making his case that the Federal Reserve "should avoid giving a structural interpretation to high capacity utilization." As we shall see, Shapiro steps into the fatal pitfall of confusing changes in absolute prices, which the Federal Reserve should care about, with changes in relative prices, about which it should not.

The main problem with the measurement part of Shapiro's paper is that he does not make an adequate distinction between measurement issues and conceptual issues, as he could have by examining more closely industries with good measures of physical output and capacity. In such industries, it becomes clear that, even when the measurement issues are completely absent, it is impossible to interpret a given level of a utilization index as indicating a given degree of "tightness." For instance, in electric utilities and airlines, two industries with excellent physical measures of output and capacity and minimal pure measurement problems, changes in the level of peak utilization over five- or ten-year intervals indicate nothing about the tightness of the economy or the likelihood of future price increases.

For electric utilities, highest feasible utilization can be physically 
measured for an instant but becomes vague for any longer period of time, because of the need to shut down capacity for maintenance. Optimal economic utilization on an annual basis depends on seasonality, which has become increasingly important with the growth of air conditioning; on changes in the relative price of fuel and maintenance; and on environmental regulations that have required the installation of antipollution equipment that adds substantially to maintenance requirements. Thus although utilization in the electric utilities has dropped sharply since 1973, we have no idea how much of the drop represents slack capacity available to be utilized on a permanent basis.

For airlines, we have excellent data on load factors, that is, traffic divided by seat-miles flown. But this is only one of several possible utilization rates. Seat-miles flown itself is a choice variable equal to a daily utilization percentage times the total number of seat-miles that could be flown if all planes were operated 24 hours a day. Multiplying the two together would yield a third rate, the percentage of total physically feasible flying, which, as in the case of the electric utilities, could not be sustained for long before maintenance requirements set in. And all three utilization rates are affected, among other things, by pricing regimes. When prices were regulated, costs escalated mainly through the device of low load factors, which provide more passenger comfort. Deregulation and the era of People Express brought a quantum increase in load factor, but with the establishment in the past two years of a pricing cartel, a transition to a higher price, lower load-factor regime has begun. Again, the level of utilization tells us nothing about the tightness of the economy.

It is, however, on the broader issue of macroeconomic policy that I find myself in strong disagreement with this paper. Shapiro's central policy objective is to evaluate the conventional view that "if capacity constrains real output growth, inflation must increase." He aims to "evaluate the theory and evidence on the link between capacity utilization and price change." At the end the author concludes that "high measured capacity utilization does not imply that the economy has hit a barrier to further growth. Consequently, high measured utilization per se should not signal to the Federal Reserve that interest rates should be raised or that the growth rate of the money supply should be slowed."

Thus Shapiro appears to join with Bradford DeLong and Lawrence Summers (BPEA, 2:1988, pp. 433-80) as an advocate of a new school of 
thought in U.S. macroeconomics, the view that any level of utilization observed in history is feasible and therefore that no speed limits should be imposed by the monetary authorities. Since this new school of thought has not yet been given a name, I would like to christen it autobahn economics, the economics of living without speed limits. In autobahn economics the world is characterized by hysteresis effects, like those evident in data for Germany and for Europe as a whole, as I discussed here a year ago (BPEA, 1:1988, pp. 271-304).

In my view, the empirical evidence against autobahn economics is very strong in U.S. postwar data, Shapiro provides no shred of evidence in its favor, and there are good reasons for the Federal Reserve to pay close attention to its capacity utilization index. The logic of my argument is simple and does not require looking at the econometric evidence that I discuss below. Something has convinced many people, inside and outside of the Federal Reserve, that U.S. inflation accelerates when the unemployment rate falls below a threshold-the nonaccelerating inflation rate of unemployment (NAIRU). From where else, we still ask, could the inflation acceleration of the 1960s have come but from a highpressure economy?

Shapiro's paper suffers from a common flaw in much recent macroeconomic research, the attempt to reason de novo about an issue without addressing the previous several decades of literature that helped to establish the position that it seeks to refute. Any paper that argues against a widely held view of the world, in this case the Federal Reserve's concern that high demand pressure leads to accelerating inflation, must have a research anchor to the existing literature that established that existing view and must in any new empirical results claiming to contradict that existing view provide a research bridge showing which previously established empirical relations are overturned and why. By conceding that his paper has "little to add" to "that well-known empirical regularity" (the Phillips curve), Shapiro admits openly that his paper is irrelevant to the central policy concerns of the Federal Reserve.

There are two possible interpretations of utilization data in the context of this mainstream NAIRU view. The first would be to claim that the NAIRU approach is wrong, and that the Federal Reserve should be no more concerned about the inflationary implications of a low unemployment rate than Shapiro thinks it should be about a high utilization rate. But we can learn nothing about the validity of the mainstream NAIRU 
approach from Shapiro's paper, because he never mentions the NAIRU, nor the postwar U.S. episodes of accelerating inflation, nor the research that has established the empirical connection between the unemployment rate and the acceleration of inflation.

The second interpretation accepts the mainstream view, but regards the unemployment rate as a good indicator of inflationary pressure while regarding the utilization rate as a bad measure. We learn nothing about this second interpretation from Shapiro's paper either, because he omits any mention of the correlation between the unemployment and utilization rates, and none of his tests shows that the utilization rate fails to explain the acceleration of inflation in an empirical context in which the unemployment rate succeeds. The Federal Reserve will rightly ignore the policy section of the paper, because those who believe that a high utilization rate leads to accelerating inflation will not find any evidence that bears on the four ways in which the utilization rate could be a useful indicator in FOMC meetings: first, utilization by itself could be a better predictor of inflation than unemployment by itself; second, utilization could make a marginal contribution to explaining inflation even in equations that include unemployment; third, utilization could be a superior variable if it does not require adjustments for demographic shifts and other such sector-specific developments that cloud the cyclical interpretation of unemployment data; and fourth, unemployment could lag utilization, so that utilization could be a more useful indicator than unemployment simply because news of its cyclical turning points arrives earlier than news about unemployment. I shall provide here evidence to assess all four of these reasons why the utilization rate might be a useful cyclical indicator and conclude below that the first and third reasons are correct, while there is no evidence to support the second or the fourth.

Even more basic than Shapiro's failure to consider the marginal information content of the utilization rate as compared with the unemployment rate is his confusion of relative and absolute prices. The mission of the Federal Reserve is to control the rate of change of the absolute price level. But Shapiro's negative conclusions about utilization are based on evidence regarding relative prices, not absolute prices. Shapiro believes that the central empirical issue is the predictive power of utilization for the change in the price-wage margin-a relative pricerather than the change in the absolute price level. Even though Shapiro himself shows that utilization is highly significant in an equation for the 
change in the absolute price level, ${ }^{1}$ he dismisses this result by saying that "this correlation should not be given a structural interpretation that depends on tight capacity."

Shapiro has it backwards. It is the evidence on margins that the Federal Reserve should dismiss, and it should care deeply about the evidence on absolute price changes. As we shall see, the positive correlation of capacity utilization with the aggregate inflation rate is much more significant statistically than it is in Shapiro's industry data. There should be no surprise that price-wage margins exhibit no strong evidence of procyclical movements. The price-wage margin, prior to adjustment for productivity change, is after all just the inverse of the real wage, and, more than 50 years after Keynes' General Theory, evidence favoring significant countercyclical movements in the real wage has yet to surface. It is theoretically possible for the price-wage margin and the real wage to be absolutely fixed over the business cycle and yet for excess demand to pull up the rate of change of prices and wages together. In a period of high demand, after all, a firm not only is able to raise prices, but also finds it harder to resist demands for higher wages. However, as we shall see, the price-wage margin has neither been constant nor countercyclical. Instead, its postwar behavior is dominated by a major swing taking place over several business cycles.

Turning to my new econometric evidence, I first focus on the relation between the utilization rate and either the official unemployment rate or my unemployment "gap" variable. ${ }^{2}$ To save space, these first-step results are merely summarized here, not displayed in a separate table. All results are based on quarterly equations that include a constant, a time trend, and time squared; when a lagged variable is included, it is always with four lagged values. When a regression is run of the utilization rate on the current and lagged unemployment rate, there is a significant positive time trend coefficient that vanishes when the unemployment rate is replaced by the unemployment gap. This suggests that one possible merit of the utilization rate series-unlike unemployment, where a demographic adjustment appears to be necessary to achieve an adequate demand pressure variable like the unemployment gap series-is that the

1. In his table 7 , the significance level of utilization for the price level in total manufacturing is 0.01 .

2. The unemployment gap is defined as the official unemployment rate minus my estimate of the "natural unemployment rate." See Gordon (1985). 
raw utilization rate series without adjustment captures the same basic cyclical process. The residual movements in utilization that are not explained by current and past values of the unemployment gap display serially correlated fluctuations between +3 percent and -4 percent, with high values in the mid-1960s and late 1970s, and low values in the early 1970s and small negative values in 1987-88.

Do the utilization rate and the unemployment gap contain the same information about the business cycle, or do they contain some independent information? In a Granger-causality framework, where each is regressed on lagged values of itself and the other variable (with no current value of the other variable included), it appears that both "cause" each other at better than a 1 percent significance level. Thus the two indicators contain independent information and are not mirror images of each other. Interestingly, the significance of lagged unemployment for current utilization is greater than that of lagged utilization; I interpret this to indicate that the recent history of utilization is dominated by highfrequency movements, while the lower-frequency movements of the unemployment rate series do a better job in predicting the current utilization rate.

Which provides a better explanation of inflation: the utilization rate, the unemployment gap, or both together? This question is addressed in equations explaining the quarterly change in the fixed-weight GNP deflator in the first two columns of table 1 . The utilization or unemployment gap variables are entered as just the current level and current change, with no lags. This simple specification fits only slightly worse than the alternative that I usually employ (fitting unconstrained coefficients to the current value and four lags) and is preferable here because the relative importance of level and change effects is readily visible. Recall that the level effect must be absent for pure hysteresis effects to be present and for autobahn economics to be vindicated.

Whatever the merits of autobahn economics as a description of European data, columns 1 and 2 show that it is decisively rejected for the United States and that it makes no difference whether the utilization rate or unemployment gap is used as the indicator of demand pressure. The significance of the level of either in an exclusion test occurs at better than the 1 percent level for unemployment and better than 0.1 percent for utilization. Yet for autobahn economics to be valid, the level term must be insignificant. 
Table 1. Equations Explaining the Quarterly Percentage Change in the Fixed-Weight GNP Deflator and in the Price-Labor Cost Margin, 1955:1-1988:4a

\begin{tabular}{|c|c|c|c|c|c|c|}
\hline \multirow[b]{2}{*}{ Independent variable } & \multicolumn{4}{|c|}{ Fixed-weight GNP deflator } & \multicolumn{2}{|c|}{ Margin } \\
\hline & (1) & (2) & (3) & (4) & (5) & (6) \\
\hline Constant & -8.60 & 2.19 & -6.48 & 1.58 & 5.35 & -1.53 \\
\hline $\begin{array}{l}\text { Fixed-weight deflator, } \\
\text { lagged }\end{array}$ & $\begin{array}{l}1.00 \\
(0.000)\end{array}$ & $\begin{array}{c}1.11 \\
(<0.001)\end{array}$ & $\begin{array}{c}0.93 \\
(<0.001)\end{array}$ & $\begin{array}{c}0.92 \\
(<0.001)\end{array}$ & $\cdots$ & $\cdots$ \\
\hline $\begin{array}{l}\text { Trend unit labor cost, } \\
\text { lagged }\end{array}$ & $\ldots$ & $\cdots$ & $\begin{array}{l}0.11 \\
(0.26)\end{array}$ & $\begin{array}{c}0.20 \\
(0.16)\end{array}$ & $\ldots$ & $\cdots$ \\
\hline $\begin{array}{l}\text { Price-labor cost margin, } \\
\text { lagged }\end{array}$ & $\ldots$ & $\cdots$ & $\ldots$ & $\cdots$ & $\begin{array}{c}1.26 \\
(<0.001)\end{array}$ & $\begin{array}{c}1.28 \\
(<0.001)\end{array}$ \\
\hline Utilization level & $\begin{array}{c}0.11 \\
(<0.001)\end{array}$ & $\ldots$ & $\begin{array}{l}0.08 \\
(0.02)\end{array}$ & $\ldots$ & $\begin{array}{r}-0.06 \\
(0.06)\end{array}$ & $\ldots$ \\
\hline Utilization change & $\begin{array}{c}0.04 \\
(<0.001)\end{array}$ & $\ldots$ & $\begin{array}{l}0.04 \\
(0.003)\end{array}$ & $\ldots$ & $\begin{array}{c}0.04 \\
(0.02)\end{array}$ & $\ldots$ \\
\hline Unemployment level & . & $\begin{array}{l}-0.43 \\
(0.001)\end{array}$ & $\ldots$ & $\begin{array}{r}-0.33 \\
(0.04)\end{array}$ & $\ldots$ & $\begin{array}{l}0.28 \\
(0.007)\end{array}$ \\
\hline Unemployment change & $\ldots$ & $\begin{array}{c}-0.91 \\
(0.003)\end{array}$ & $\ldots$ & $\begin{array}{l}-0.84 \\
(0.008)\end{array}$ & $\ldots$ & $\begin{array}{c}-0.33 \\
(0.39)\end{array}$ \\
\hline \multicolumn{7}{|l|}{ Summary statistic } \\
\hline $\bar{R}^{2}$ & 0.85 & 0.84 & 0.85 & 0.85 & 0.46 & 0.47 \\
\hline Standard error of estimate & 0.95 & 0.98 & 0.94 & 0.96 & 1.32 & 1.31 \\
\hline Durbin-Watson & 1.95 & 1.87 & 2.03 & 1.94 & 2.00 & 1.95 \\
\hline
\end{tabular}

a. Numbers in parentheses are significance levels of exclusion test.

For details of variable definition, specification, and choice of lag length, see Gordon $(1988$, table 1) with one exception: the list of supplementary "supply shift" variables was reduced by eliminating consumer price, minimum wage, and tax variables. This leaves as additional variables, beyond those shown here, the productivity deviation, food-energy price effect, relative import price, and Nixon controls "off" and "on." Sources and methods for the unemployment gap and the supplementary "supply shift" variables are provided in Gordon (1985).

If only one variable, the utilization rate or unemployment gap, had to be chosen, the table reveals two reasons to prefer utilization. First, the standard error is lower in column 1 than in column 2. Second, the sum of coefficients on lagged inflation in column 1 is almost precisely unity, so that this equation has an exact natural rate interpretation, without any need to constrain the coefficient. In contrast, the sum of coefficients on lagged inflation in column 2 is significantly above unity, indicating that inflation accelerates when the unemployment gap series is zero; this implies in turn that my underlying natural rate of unemployment estimate is too optimistic for part or all of the sample period. Finally, the utilization rate series has the great advantage that, unlike the unemployment gap series, it is a raw data series used without any of the convoluted and 
somewhat ad hoc adjustments that go into my estimate of the natural unemployment rate. ${ }^{3}$

To calculate the NAIRU for utilization implied by column 1, I divide the constant by the coefficient on the utilization level and reverse the sign, giving a "utilization NAIRU" of 81.0 percent. By this measure the January 1989 rate of 84.8 percent was well into inflationary territory. The corresponding constant-inflation rate for the unemployment gap cannot be calculated from column 2 , since the sum of coefficients on lagged inflation is not unity.

Is there any case for including both the utilization rate and unemployment gap in the inflation equation? Multicollinearity prevents sensible estimates when both variables are included together. But a test of marginal predictive power is provided when we add to equations 1 and 2 the level and change in the residuals from the Granger-causality equations for, respectively, the unemployment gap and utilization, as discussed above. None of the residuals is significant; the closest is the level of the utilization residual, which is significant at just the 15 percent level when included in column 2.

Since Shapiro stresses the behavior of price-wage margins, the equations in table 1 are reestimated to provide results for the aggregate economy parallel to his for manufacturing. Columns 3 and 4 add lagged changes in trend unit labor cost, with the same lag format as the lagged price variable. The results restate my 1988 finding that the U.S. price and wage processes live separate lives, and that "the markup hypothesis is dead." ${ }^{4}$ Lagged labor cost changes do not Granger-cause inflation in equations that include lagged inflation. Substantively, this result reflects a major upward swing in labor's income share between 1964 and 1978, and a major downward swing from 1978 to 1988. For whatever reason, firms did not fully mark up labor costs before 1978 and more than marked them up after 1978, and so any tests (like Shapiro's) that rely on secular stationarity in the markup ratio are flawed. And, because lagged labor costs are insignificant in columns 3 and 4, the equations omitting labor

3. What happens when the unadjusted official unemployment rate series is used in column 2 instead of the unemployment gap used in the table? It is just as significant statistically, but now the sum of coefficients on lagged inflation rises to 1.16 , indicating that a constant NAIRU for unadjusted unemployment cannot explain the extent of inflation's acceleration in the data.

4. Gordon (1988, p. 280). 
costs in columns 1 and 2 are preferable and provide the proper measure of the statistical significance of utilization and unemployment.

The final results are presented in the two right-hand columns, where changes in the price-to-labor-cost margin are regressed on their own lagged values and the same set of additional explanatory variables as in the other columns. Here we see why Shapiro's evidence of a weak relation between utilization and margins is unconvincing; the weak relation in column 5 does not preclude, and in fact is completely consistent with, the finding of extremely high significance in column 1 . Is the markup procyclical and the real wage countercyclical? The answer is a mild yes. Since the dependent variable is the change in the markup, what matters is the coefficient on the change in utilization, which is significantly positive in column 5 at the 2 percent level (but insignificant in column 6).

My earlier remarks on the conceptual weakness of utilization indexes even in well-measured industries like airlines and electric utilities may seem to pose a paradox. How can something so fragile conceptually perform so well empirically in an aggregate inflation equation like that in column 1 ? One reaction is to predict that Lucas's critique will doubtless lead the utilization-inflation relation to fall apart any day now. In light of the stability of this type of Phillips curve relation over the past decade, I would prefer another interpretation-a law of large numbers causes the conceptual problems of utilization measures in individual industries to wash out and become unimportant at the aggregate level.

This brings us to the empirical evidence in Shapiro's paper. Most of the tests ask whether high capacity utilization signals constraints on output growth, and there is only a short section on the relationship between utilization and prices. I would have reversed these proportions, because the negative results on high utilization signaling output constraints have no implications in principle for what matters, the effect of high utilization on inflation. As Shapiro's own earlier discussion indicates, feasible engineering capacity is often much higher than economically optimal capacity, so inflation pressures can begin without the economy ever running into physical barriers. To convince yourself of that, think of 1942, when manufacturing capacity utilization was doubtless higher than in any year of the postwar era, and yet the output of durable goods grew another 70 percent between 1942 and 1944. With such an extreme episode so evident in the historical annals, how could 
Shapiro possibly have expected any convincing evidence of capacity constraints to have emerged from postwar data?

This leaves Shapiro's tests of the relation between utilization and prices in his table 7. My major objection, already stated, is that high utilization can lead to accelerating inflation without any need for the price-wage margin to be procyclical. He implicitly concedes that his tests are irrelevant for the Federal Reserve when he states that they evaluate "whether capacity utilization is priced above these increases in cost due to higher wages at higher levels of activity"-obviously the Federal Reserve cares about faster inflation even if it reflects only faster growth in labor cost. Shapiro's tests seem to embody an unsupported dichotomy, that utilization matters only for price markups over wages and that something else, maybe unemployment, matters for wages, but, as we have seen, utilization and unemployment are so highly correlated that if one matters for prices or wages, so does the other. Stated another way, Shapiro's paper omits the key step of asking whether utilization matters for the wage changes that he erroneously takes as exogenous.

Finally, at the level of implementation, Shapiro's tests are severely flawed by defining the margin as the ratio of the price level to the wage rate rather than the ratio of the price level to trend unit labor cost. ${ }^{5}$ With productivity growth in manufacturing varying from 2.9 percent during $1948-73$, to 1.4 percent during $1973-79$, to 3.5 percent during $1979-87$, any relation between Shapiro's estimate of the margin and the actual margins as viewed by businessmen is highly unlikely. His estimated equations provide no information at all on "rising short-run marginal labor costs," since they are based on data for raw wage rates rather than trend or actual unit labor costs.

Lawrence H. Summers: Matthew Shapiro's paper attacks the Federal Reserve Board's capacity utilization variable from many perspectives. A reader of the paper is left with the impression that as an economic variable, capacity utilization ranks somewhere between hem lengths and sunspot activity in terms of relevance. Shapiro's principal uncer-

5. The inclusion of trend unit labor cost does not preclude an influence of actual unit labor cost, defined as the wage rate divided by actual labor productivity. By including the deviation of productivity from trend in all the equations in table 1 (as in all such equations that I have published in BPEA over the past 20 years), I allow the computer to choose the weights in price determination of trend and actual productivity movements. 
tainty is over whether capacity utilization variables fail because they are mismeasured or whether, instead, their failure suggests the need for radical emendations to traditional macroeconomic models.

Shapiro indicts capacity utilization variables on three counts, none of which I find terribly persuasive. First, he argues that their construction is based on incoherent and confused theory. Second, they do not make the predictions they should about the distribution of output shocks, if output does in fact run up against capacity constraints. Third, capacity utilization variables do not predict inflation in the way they should. I will consider these points in turn.

First, Shapiro argues that the concept of capacity used in constructing utilization measures is an uneasy balance between engineering and economic capacity. Here, he makes a particularly striking point when he questions the logic of seasonally adjusting utilization figures since capacity is probably relatively constant over time. He is surely right that there is no well-defined concept of aggregate capacity in an economy like ours.

On the other hand, if one accepts the idea that there are times when the economy is hot and times when it is cold, or the related notion that sometimes excessive demand pressure threatens to cause inflation to accelerate, there has to be some standard of comparison for today's output. One standard procedure is to work with output relative to some possibly sophisticated measure of trend growth. This is not avoiding the capacity issue. It is simply sidestepping it by assuming that growth in capacity is smooth. A priori it seems reasonable that one can do better by asking people questions about how much room they have to expand output.

Criticism like Shapiro's can be and have been levied against unemployment rates as a measure of labor market pressure. No measure is perfect conceptually, so, as Shapiro recognizes, choices have to be made on empirical grounds. The second part of his paper is directed at a variety of tests of the predictive power of capacity utilization for output shocks, measures of unfilled orders, and measures of vendor performance. Capacity utilization does not come out looking great. This finding would be more impressive, however, if Shapiro had found other variables that did better. There is no question that short-term forecasts of the variables Shapiro studies can be improved on by using variables other than capacity utilization. Otherwise, real forecasters would not do much better than 
Shapiro's autoregressions. Until Shapiro finds some variables that work, I will continue to harbor the suspicion that his variables reflect on his tests as much as on the capacity utilization variable.

There is some information in Shapiro's finding that output shocks appear no more skew when capacity utilization is high than when it is low. I wonder, however, whether this does not reflect the fact that capacity can always be greatly varied in the short run in response to crisis, even if not permanently. I think here of firms' ability to defer maintenance at times when order flow is especially strong. It would be interesting to see if the extent of evidence for skewness differed among monthly, quarterly, and annual data.

Shapiro recognizes that the key idea underlying most uses of the capacity utilization statistics is the notion that they predict inflation. $\mathrm{He}$ tests this notion by estimating vector autoregressions relating prices to wages, capacity utilization, and oil prices and again finds little predictive power for capacity utilization. This may not be as surprising as it first appears. We know that there is a tendency for real wages to be procyclical, as is capacity utilization. It is therefore to be expected that prices will not rise given wages when capacity utilization is high. As in the case of his other tests, Shapiro's evidence here would be stronger if he could find other variables that worked where capacity utilization failed. I don't feel ready quite yet to throw out the law of supply and demand's implication that more demand means higher prices.

Despite all these qualifications, Shaprio's evidence is distressing to those like me with strong prior beliefs that cyclical fluctuations reflect demand shocks. They are worrying because they come alongside other evidence that also points toward a role for supply shocks in cyclical fluctuations. Consider some examples. Productivity, no matter how measured, is higher in booms than busts. Real wages are higher and so are profits in booms. Firms decide to accumulate not decumulate inventories in booms. This is what one would expect if booms were cheap times to produce. The economy does not tend to run larger trade deficits in booms than in busts as would be predicted by a model in which fluctuations in output were caused only by demand shocks.

These facts all point toward a supply shock element in booms. Where does it come from? One possibility is that the apparent supply shock results from increasing returns. Another is that expansionary monetary policy that reduces credit costs acts like a favorable supply shock. Yet 
another (least plausible) possibility is that booms result from technological shocks, as Edward Prescott has argued. Distinguishing these possibilities is an important area for future research.

I conclude with one policy implication of Shapiro's results. Fears that capacity constraints will make output growth impossible, whether in the context of the United States during World War II, U.S. export industry today, or the allegedly capital-short economies of Europe, are unwarranted. Capacity constraints should not be taken as an argument that expansion is impossible. But I think it is premature to take the extreme view that capacity constraints should not cause policymakers to worry about the price implications of expansion.

\section{General Discussion}

Robert Hall interpreted Shapiro's central finding to be that the level of capacity utilization has little or no effect on output or pricing decisions. This, he noted, supports the view that the product supply curve is highly elastic. One explanation is that firms' marginal cost curves are flat. Another explanation, implicit in Peter Diamond's work, is that there are positive externalities to production; even though marginal cost schedules of individual firms may slope upward, they shift down when the economy expands, tracing a flat locus with respect to macroeconomic fluctuations. With supply curves flat, Hall reasoned that the Federal Reserve should not be targeting real variables such as capacity utilization or unemployment because it cannot know what levels are appropriate. He advocated targeting nominal GNP growth.

Although granting that we do not know the long-run limits for unemployment or utilization, Christopher Sims cautioned against Hall's single nominal target. Real variables may help predict both nominal GNP and inflation, and they should help guide monetary policy in view of the delays in the effects of policy on nominal variables. Sims emphasized the importance of Shapiro's finding that the dispersion of production surprises is exceptionally small at high capacity utilization. Such a finding strongly suggests a nonlinearity in the movement of output that is not consistent with a flat marginal cost curve. Shapiro noted that if marginal cost curves were not flat, one should find that production changes have a lower mean at high utilization, something that is not statistically supported in his data. But William Brainard observed that, 
with order backlogs varying, output dispersion rather than mean would be the right test. If demand for the firm's output follows a random walk with zero mean, variations in demand at high capacity utilization would increase or decrease order backlogs with little variation in output and an unchanged mean. Below full capacity, output would follow the random walk of demand, which has mean zero as before but much higher variance.

William Nordhaus reported that the raw data on capacity show a positive correlation between output and capacity shocks. However, these shocks are filtered out of published series. Nordhaus wondered whether such filtering results in a loss of information that would be useful in interpreting utilization data. Nordhaus also suggested that Shapiro's price equations would be more informative if they included material prices and import price variables as explanatory variables along with wages. Previous work has found mixed results on the impact of capacity utilization on prices once all cost elements are included. It would be interesting to see whether the markup behavior of businesses has changed over the past decade because of the increased penetration of imports and importance of foreign competition.

Richard Raddock reported that, in recent years, the capacity measures have been especially useful because they have revealed reductions in capacity in major industries including aluminum, steel, and petroleum refining. In those primary processing industries, where good data exist and where utilization rates have gotten high, he reported observing rapidly rising prices and profit margins and reports by purchasing managers that product is in short supply.

Shapiro, in reply to the discussion, stated that Gordon's findings concerning the role of capacity utilization in the Phillips curve are consistent with the findings of the paper. Gordon finds that capacity utilization has little incremental explanatory power in an inflation equation that also includes the unemployment rate. Measured capacity utilization is a business cycle indicator, but carries no added information about tightness of capacity per se. Similarly, the regressions reported in the paper show that virtually all the increase in prices that occurs when capacity utilization is high is a reflection of higher wages, not of scarce capacity. 


\section{References}

Barsky, Robert B., and Jeffrey A. Miron. 1989. "The Seasonal Cycle and the Business Cycle." Journal of Political Economy 97:503-34.

Blanchard, Olivier J., and Danny Quah. 1988. "The Dynamic Effects of Aggregate Demand and Aggregate Supply Disturbances." Working Paper 2737. Cambridge, Mass.: National Bureau of Economic Research (October).

Board of Governors of the Federal Reserve System. 1978. Federal Reserve Measures of Capacity and Capacity Utilization. Washington.

— 1986. Industrial Production, 1986 Edition. Washington.

1989. "Record of Policy Actions of the Federal Open Market Committee." Federal Reserve Bulletin 75:66-71.

Bureau of the Census. 1987. Survey of Plant Capacity, 1986. Current Industrial Reports. Washington: Department of Commerce.

Bureau of Economic Analysis. 1977. Business Conditions Digest. Washington: Department of Commerce (July).

Campbell, John Y., and N. Gregory Mankiw. 1987. "Are Output Fluctuations Transitory?" Quarterly Journal of Economics 102:857-80.

Carlton, Dennis W. 1986. "The Rigidity of Prices." American Economic Review 76:637-75.

Cooper, Russell, and Andrew John. 1988. "Coordinating Coordination Failures in Keynesian Models." Quarterly Journal of Economics 103:441-64.

Coutts, Kenneth, Wynne Godley, and William Nordhaus. 1988. Industrial Pricing in the United Kingdom. Cambridge: Cambridge University Press.

De Long, J. Bradford, and Lawrence H. Summers. 1988. "How Does Macroeconomic Policy Affect Output?" BPEA, 2:1988, pp. 433-80.

Eckstein, Otto, and David Wyss. 1972. "Industry Price Equations." In The Econometrics of Price Determination (conference proceedings). Washington: Board of Governors of the Federal Reserve System.

$\rightarrow$ Gordon, Robert J. 1988. "The Role of Wages in the Inflation Process." American Economic Review, Papers and Proceedings, 1987 78:276-83.

- 1985. "Understanding Inflation in the 1980s." BPEA, 1:1985, 263-99.

Greenspan, Alan. 1989. Statement before the Committee on Banking, Finance, and Urban Affairs, U.S. House of Representatives (January 24).

Hall, Robert E. 1988. "Noise." Okun Lectures, Yale University.

Kendall, Maurice G., and Alan Stuart. 1977. The Advanced Theory of Statistics, vol. 1. New York: Macmillan.

Klein, Lawrence R., and Virginia Long. 1973. "Capacity Utilization: Concept, Measurement, and Recent Estimates.” BPEA, 3:1973, 743-56. 
Miron, Jeffrey A., and Stephen P. Zeldes. 1988. "Seasonality, Cost Shocks, and the Production Smoothing Model of Inventories." Econometrica 56: 877-908.

1989. "Production, Sales, and the Change in Inventories: An Identity That Doesn't Add Up.' Journal of Monetary Economics (forthcoming).

Mood, Alexander M., Franklin A. Graybill, and Duane C. Boes. 1974. Introduction to the Theory of Statistics, 3rd ed. New York: McGraw-Hill.

Murphy, Kevin M., Andrei Shliefer, and Robert W. Vishny. 1989. “Building Blocks of Market Clearing Business Cycle Models." NBER Macroeconomics Annual 4 (forthcoming).

Nelson, Charles R., and Heejon Kang. 1981. "Spurious Periodicity in Inappropriately Detrended Time Series." Econometrica 49:741-51.

Perry, George L. 1973. "Capacity in Manufacturing,' BPEA, 3:1973, 701-42.

Prescott, Edward C. 1986. "Theory Ahead of Business Cycle Measurement." Carnegie-Rochester Conference Series on Public Policy 25:11-44.

Raddock, Richard D. 1985. "Revised Federal Reserve Rates of Capacity Utilization." Federal Reserve Bulletin 71:754-66.

Ramey, Valerie. 1988. "Non-Convex Costs and the Behavior of Inventories." University of California, San Diego.

Shapiro, Matthew D., and Mark W. Watson. 1988. "Sources of Business Cycle Fluctuations." NBER Macroeconomics Annual 3:110-48.

Sichel, Daniel. 1989. "Are Business Cycles Asymmetric? A Correction." Journal of Political Economy (forthcoming).

Silverman, B. W. 1986. "The Kernel Method for Univariate Data." In Density Estimation for Statistical Analysis. London: Chapman and Hall. 